\title{
ESTRUCTURAS NOMINALES, VERBALES Y ORACIONALES DEL TEXTO LEGAL
}

\author{
HERMINIA PROVENCIO GARRIGÓS \\ (Universidad de Murcia)
}

\begin{abstract}
This paper presents a proposal for the formalization of nominal and verbal structures and the syntax of legal texts, focusing on the Spanish Constitution and the Autonomic Statute of the Region of Murcia. The theoretical basis is drawn from considering the Spanish Constitution as the thematic and verbal paradigm of the Statute, in both its discursive and textual design. This design is influenced by law topics, inherent to both texts, which show similar morphosyntactic structures and share the same high level of lexicalization.
\end{abstract}

\section{Conocimiento de los textos objeto de análisis}

En la determinación de los textos sobre los que se va a desarrollar el análisis se ha configurado como criterio general el ser jurídicos y como criterio específico el legal, y dentro de este último el estatutario, siendo el estatutario la Ley Orgánica 4/1982, de 9 de junio, de Estatuto de Autonomía de la Región de Murcia ; esta ley es el centro de la formulación teórica de este estudio, pero para realizar un análisis preciso hay que mirar hacia su dimensión intertextual en la que nos encontramos con el texto del que es deudor: la Constitución española ${ }^{2}$.

El ordenamiento jurídico-constitucional genera textos como son los Estatutos de Autonomía. El EA, al igual que el resto de los pertenecientes a las distintas

\footnotetext{
' En adelante lo citaremos como EA. Dentro del grupo genérico de los textos legales se encuentran: la Ley Suprema del Estado o la Constitución, la Ley Orgánica, la Ley Ordinaria, el Decreto-Ley, el Decreto-Legislativo, la Sentencia, la Orden Ministerial, la Resolución, el Reglamento, el Acuerdo, el Auto, etc. En la obra de Martín, Ruiz, Santaella y Escánez se pueden encontrar ejemplificaciones para dichos tipos de textos (1996:61-67).

${ }^{2}$ En la adelante la citaremos como $\mathrm{CE}$.
} 
Comunidades Autónomas de España, es norma básica con rango de Ley Orgánica, que establece y reglamenta la autonomía de una Comunidad. En su estructura se recogen, básicamente, las competencias de la Comunidad y la regulación de los tres órganos institucionales: la Asamblea Regional, el Presidente de la Comunidad y el Consejo de Gobierno (Fig. 1). El resto de títulos y capítulos hacen referencia a la Administración de Justicia, la Hacienda y la Economía, el Régimen Jurídico y el procedimiento de reforma del EA.

La proyección temática y verbal de la CE hacia el EA es prácticamente unánime, excepto en el Título II, las Disposiciones Adicionales, Transitorias, Derogatoria y Final, que no tienen su reflejo en el EA. En principio, se podría pensar que su proyección se produciría sólo desde el Título Octavo de la CE, que versa sobre la organización territorial del Estado, o, incluso, desde su Capítulo Tercero referido a las Comunidades Autónomas; pero no es así, ya que no existe título en la CE que no vea su proyección en el EA. Incluso los Títulos, a los que antes se hacía referencia, sobrc la Administración de Hacienda, etc., encuentran su parangón. De forma visualizada se puede ver en el esquema de la figura 1 una primera proyección en el nivel de títulos, capítulos y secciones. Se ha intentado realizar la equivalencia de los microtextos en los índices que nos proporcionan, ilustrando en sombreado el título octavo, que, como se dijo antes, dispone sobre la organización territorial y, en especial, de las Comunidades Autónomas.

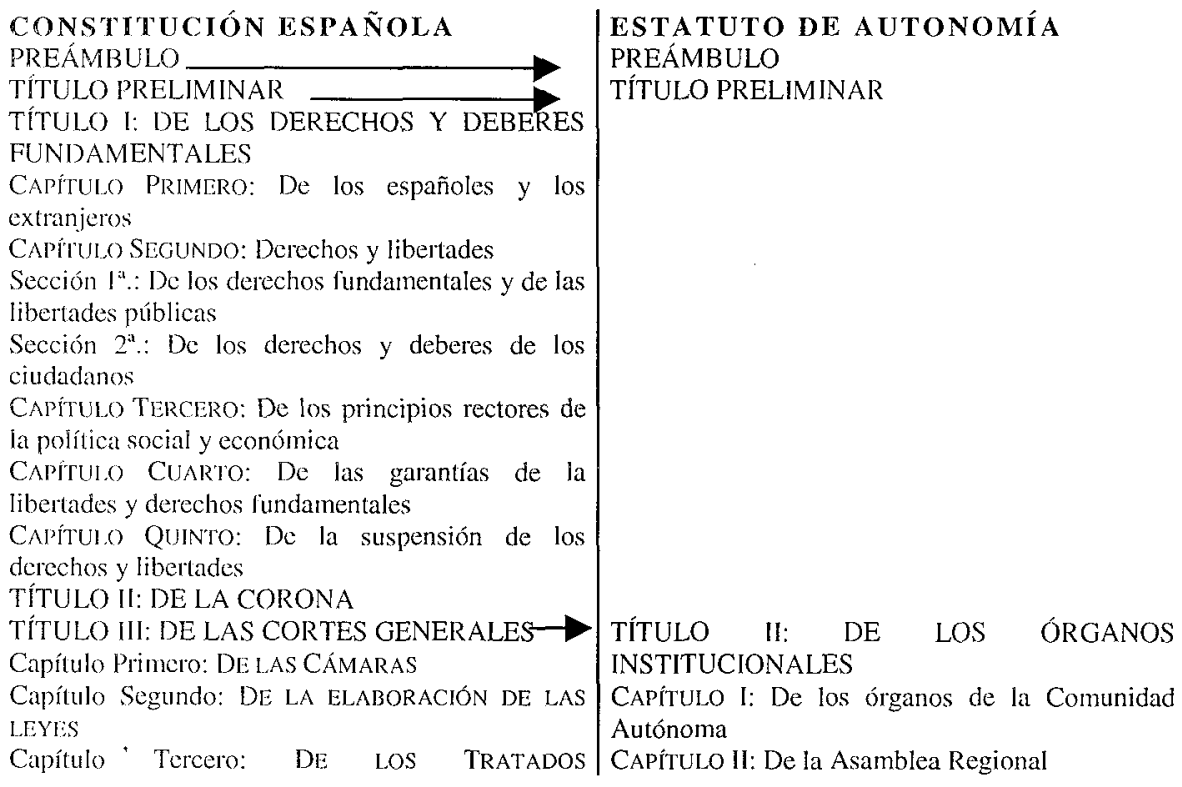


INTERNACIONALES

TÍTULO IV: DEL GOBIERNO Y DE LA ADMINISTRACIÓN

TÍTULO V: DE LAS RELACIONES ENTRE EL GOBIERNO Y LAS CORTES GENERALES

TITULO VI: DEL PODER JUDICIAL

TÍTULO VII: ECONOMIA Y HACIENDA $\longrightarrow$

TITULO VIII: DE LA ORGANIZACIONN TERRITORIAL DEL ESTADO

CAṔTULO PRIMERO: Principios generales (137(39) $)^{3}$

CAṔ́tUllo SECUNDO: De la Administración Local (140-142)

Capítulo Tercero: de las Comunidades Autónomas (143-158)

TÍTULO IX: IDEL TRIBUNAL CONSTITUCIONAL

TÍTULO $X:$ DE LA REFORMA CONSTITUCIONAL

DISPOSICIONES ADICIONALES

DISPOSICIONES TRANSITORIAS

DISPOSICIÓN DEROGATORIA

DISPOSICIÓN FINAL

Capítulo III: Del Presidente de la Comunidad

Autónoma

CAPítulo IV: Del Consejo de Gobierno

TÍTULO V: DEL RÉGIMEN JURÍDICO

CApítulo I: De la Administración pública regional

CApítulo II: Del control sobre la actividad de los órganos de la Comunidad Autónoma

TÍTULO III: DE LA ADMINISTRACIÓN DE JUSTICIA

TÍTULO IV: HACIENDA Y ECONOMÍA

TÍTULO I: DE LAS COMPETENCIAS DE LA COMUNIDAD AUTÓNOMA DE LA REGIÓN DE MURCIA (10-19)

TITULO VI: DE LA REFORMA DEL ESTATUTO

DISPOSICIONES ADICIONALES

DISPOSICIONES TRANSITORIAS

Fig. 1

\section{Estructuras sintagmático-configuracionales}

En los dos textos existe un universo jurídico-legal compartido, que posibilita el establecimicnto de un nivel hermenéutico comparativo, que viene dado por un conjunto de principios generales y descifrables por apariciones repetitivas de unidades lingüístico-verbales, poniéndonos bajo la pista de los ámbitos temáticojurídicos comunes para esbozar la sistemática de los enunciados prototípicos en su constitución morfosintáctica, es decir, un modelo de formalización en la variación de los componentes léxicos y en su representación sintáctica ${ }^{4}$.

\footnotetext{
${ }^{3}$ La numeración se corresponde con los artículos que cada capítulo comprende.

${ }^{4}$ La fundamentación está sustentada en el modelo textual que J. Perona lleva a cabo para la lectura de la tradición foral como «transmisiones textuales que se configuran como Variantes linguiísticas, bien de las invariantes semánticas, bien de las invariantes sintácticas y léxicas» (1993:138) para la constitución de los prototipos de los enunciados hipotéticos, que se materializan en un inventario de lexías complejas de índole jurídica y oraciones con base estadística.
} 
Estaríamos frente a un grupo de estructuras conceptuales y estructuras linguísticas, en el sentido propuesto por Ferenczi (1976: 226) ${ }^{5}$. A esas estructuras las denominamos dominios temáticos, es decir, construcciones permanentes de unidades significativas en la intratextualidad e intertextualidad, que pueden ser lexicalizadas en estructuras sintagmático-configuracionales (Provencio 2000) 6 . Para la consecución del desarrollo intertextual hemos definido 168 dominios presentados, como más adelante se verá, en forma de índice, conformando así un orden lógico y coherente de líneas temáticas representativas que incluyan propiedades de los dos textos. Las palabras que pueden ser definidas como entidades significativas en sus esquemas léxico-configuracionales recubren el diseño conceptual creado para la totalidad del corpus y nos permite acceder a una lectura no lineal del mismo.

Los dominios necesitan de una verbalizalización, de una expresión lingüística y se lexicalizan de diferente modo (Rastier 1995: 224, 227, 245) en la sintagmática cnunciativo-legal, que quedarían representados por: formas o unidades univerbales y pluriverbales. Su presencia o ausencia estará condicionada por su nivel de lexicalización, que hemos establecido en una frecuencia igual o superior a dos. Se admitirá, por norma general, que la repetición de determinados fenómenos suministra información para decir que se está ante una estabilidad (Thom 1985: 12); lo mismo ocurre con las estructuras sintagmáticas, que deben guardar cierta unidad y frecuencia para ser consideradas como tales combinaciones e identificadas como unidades individuales. En el texto legal se observa que se produce la selección de unidades verbales de forma recurrente, con lo que se vislumbra la existencia de un proyecto discursivo textual previo, que excede los límites del propio texto ${ }^{7}$. Creemos acertada el razonamiento de Alvar Ezquerra, que

\footnotetext{
${ }^{5}$ Esta orientación supone aceptar que el texto es una globalidad (García Berrio y Albaladejo 1983: 13I) y, al mismo tiempo, considerar el modelo teórico planteado por Van Dijk en el que se determinan los conceptos de macroestructura, microestructura y superestructura (1996: 54-78).

"Utilizando la propuesta de Ullman hablaríamos de «esferas conceptuales sólidamente integradas» (1977: 113) y en opinión de Duchacek: «champ conceptuel» (1970: 202). Esta forma de caracterización, como obscrva acertadamente J. L. Cifuentes, presupone considerar que «las estructuras lingüísticas forman parte del aparato cognitivo general: las categorías lingüísticas son tipos de categorias cognitivas» (1994: 154).

${ }^{7}$ Martínez Marín en un artículo sobre el lenguaje administrativo plantea la bipolaridad entre lenguaje común, que es «la modalidad lingüística más general» frente a otras modalidades propias de grupos de hablantes pertenecientes a grupos particulares, que utilizan para el intercambio comunicativo los lenguajes especiales, entre los que se incluyen el científico, el jurídico, etc. Tradicionalmente, estos últimos han sido estudiados por la corriente lexicalista, que, como su nombre indica, son considerados sólo como una modalidad léxica, relegando otros aspectos determinantes y específicos como son las consideraciones sintácticas, fraseológicas, etc. Frente a esta visión aparece la corriente pragmatista orientada hacia un planteamiento del estudio de los lenguajes especiales con un marcado carácter comunicativo, implicando de este modo el carácter específico de los contenidos que se transmiten, el léxico, lraseología, etc. (1997: 216, 217).
} 
extrapolamos a nuestro propósito, cuando al hablar sobre la inclusión o no en los diccionarios de frases, locuciones y modismos, opina que todo dependerá de su «grado de lexicalización (determinado subjetivamente por el lexicógrafo)» (1993: 100). Consideramos que lo prototípico se manifiesta tanto a nivel de sistemática conceptual como a nivel de estructuras verbales, que forman un conjunto de unidades léxicas coherentes.

Es factible establecer una tipología formalizada de microtextos verbales prototípicos, que hemos definido en unidades verbales -impregnando al adjetivo «verbal» la acepción de referirse a cualquier palabra- formadas por una o más palabras. Encuentran expresión gramatical a través de las siguientes formulaciones: nominal, verbal y oracional, pudiendo, a su vez, estar conformadas por formas del tipo: adjetival (calificativo), adverbial (incluidas las locuciones), detcrminativa (demostrativos, posesivos, numerales, indefinidos, relativos y artículo), preposicional (incluidas las locuciones), relacional (conjunciones), pronombre y oracional. Para su determinación se ha seguido el criterio de la simplicidad, es decir, no se ha realizado un clasificación exhaustiva dentro de cada categoría para cvitar la complejidad de la lectura y porque las variaciones dentro de cada uno de ellas son mínimas. Hemos aceptado los planteamientos funcionalistas propuestos por E. Alarcos Llorach (1994) y C. Hernández Alonso (1996) en la clasificación categorial establecida, aunque con algunas matizaciones impuestas por la dinámica de nuestro desarrollo, que pueden cifrarse en las siguientes: al igual que lo hiciera Hernández Alonso (1994: 558-559, 569-577) se ha incluido dentro de los determinantes el artículo, a diferencia de E. Alarcos que lo considera con características suficientes para diferenciarlo del resto de determinativos (1994: 6668). Su alternancia se presenta, generalmente, con demostrativos e indefinidos adjetivos y si se hubiera distinguido entre ellas, la captación de las estructuras resultaría demasiado costosa.

En el texto jurídico-legal se dan diversas posibilidades de construcción de unidades, de entre ellas las estructuras más productivas son las nominales, verbales y oracionales integradas por: NOMINAL \{forma nominal + forma adjetival $\}$, \{forma determinativa + forma nominal + forma adjetival $\}$, \{forma nominal + forma preposicional + forma nominal $\}$ y la formas oracionales regidas por formas verbales en \{presente $\}$ y $\{$ futuro $\}$ en su mayoría en tiempo indicativo, sin olvidar la recurrencia de $\{\mathrm{Se}+$ forma verbal: presente/futuro\}. Estas formas pueden ser consideradas como unidades terminológicas por su frecuencia y, por lo tanto, combinaciones no libres, que siéndolo serían propias del uso de la lengua en situaciones normales de comunicación (Cabré Castellví 1993: 305). Aventuramos, por tanto, la existencia de un nivel de formalización en la relación de sintagmaciones verbales que configuran la textualidad legal. Diremos que una unidad está lexicalizada cuando su frecuencia sea igual o superior a dos. 
Siguicndo la línea de investigación que propone B. Pottier, diremos que la lexía, tratada como unidad o forma, es el núcleo o concepto fundamental que se ha desarrollado en el análisis que aquí presentamos ${ }^{8}$. En consecuencia, la lexía puede ser nuestra unidad léxica operativa, o «unidad de tratamiento» (Alvar Ezquerra, 1976:23; 1993: 89).

En algunos casos se hablaría de «discurso repetido», en el sentido propuesto por Coseriu: «el «discurso repetido» abarca todo lo que tradicionalmente está fijado como «expresión», «giro», «modismo», «frase» o «locución» y cuyos elementos constitutivos no son reemplazables o re-combinables según las reglas actuales de la lengua. [...] Las unidades del «discurso repetido» son, como las citas explícitas, trozos de discurso ya hecho introducidos como tales en nuevos discursos» (1977: 113); aunque es posible encontrarse con combinaciones en las que un elemento como el verbo puede conjugarse, Coseriu lo ejemplifica con ««se moquer» + du ticrs comme du quart» (1977: 114), pero añade que sus elementos no pueden ser «conmutables». Estas unidades se enfrentarían con las que pertenecen a la «técnica del discurso». Por lo tanto, estaríamos frente a unidades del discurso repetido y unidades de la técnica del discurso, pudiendo pertenecer una unidad a los dos ámbitos.

El desarrollo pondrá de manifiesto la utilización reiterativa dentro de los segmentos textuales seleccionados de ciertas unidades y grupos léxicos formando parte de cstructuras oracionales. Este hecho manifestativo-textual pone de relieve la existencia de condicionantes extratextuales, pudiéndose estipular una «tipología de las distintas clases de sintagmas discursivos» (Ramón Trives 1999: 164). Greimas y Landowski consideran que «el discurso jurídico puede ser reconocido como tal si comporta, de forma recurrente, un cierto número de propiedades estructurales que lo dilerencian a la vez de cualquiera de los discursos cotidianos» (1980: 95); esas propiedades recurrentes, a las que se refieren, son gramaticales y léxicas.

\subsection{Sintagmática tipológico-lingüística seleccionada}

La sistemática del índice de los dominios, que introduce cada estructura, tiene su origen en cl propuesto por el propio Estatuto, es decir, se ha respetado su orden de supcrestructura, incorporando los microtextos que le acompañan, excepto en el «Preámbulo», «Título Preliminar», «Disposiciones Adicionales» y «Disposiciones Transitorias», que, por su propia naturaleza, no lo incorporan y los puntos «A. FÓRMULA PROMULGATORIA»y «L. FÓRMULA FINAL»; no hay que dejar pasar por alto

\footnotetext{
- La lexía es definida por B. Pottier como «secuencia de palabras memorizada como signo individualizado» (1993: 30) o como «la unidad lexical memorizada» (1976: 324). Para su caracterización véanse sus obras de 1971: 26 y 1993: 30.
} 
que en ambos textos se producen referencias internas y externas que remiten bien a la Constitución, bien al Estatuto; por ello el último punto como «M. REFERENCIAS EXTERNAS A LA CONSTTTUCIÓN ESPAÑOLA E INTERNAS AL ESTATUTO DE AUTONOMIA DE $L A$ REGIÓN DE MURCIA», en el que solamente hemos tenido en cuenta las que aparecen en el EA. Baste decir que el mayor porcentaje de la palabra «Constitución» se produce en el artículo 10, que se corresponde con las competencias exclusivas de la Comunidad Autónoma. El resto de conceptualizaciones, que aparecen, vienen impuestas por nuestra propia determinación. Para que la lectura sea más fácil hemos optado por el sistema de claves alfabéticas y numéricas, esto es, a continuación de la descripción del dominio se ubican las relerencias al EA y a la $\mathrm{CE}$, seguidas del número de Artículo del texto. Para realizar este índice ha sido preciso aunar los dos textos y obtener sus paralelismos; ya que, por ejemplo, un dominio puede estar distribuido a lo largo y ancho de todo el texto, o en un mismo artículo estar incluidos varios de ellos.

La primera y más significativa impresión que obtuvimos al finalizar el análisis comparativo fue que la Constitución española es el paradigma léxico y estructural del Estatuto, cs como si, y utilizamos la afirmación de aquel primer momento, se hubicra «cortado y pegado» de un texto a otro. Pero tuvimos la fortuna de cncontrar en G. Salvador un aliado para nuestra primera impresión:

...las leyes lundamentales son habitualmente el fruto de componendas políticas que acaban en desdichadas chapuzas lingüísticas, y eso no parece tener remedio. Pero a esos nivcles cxiste, al menos, la corrección de estilo y eso garantiza, si no la claridad del contenido, sí una cierta pulcritud externa.

Conforme se baja en la escala jerárquica de las disposiciones, se va perdiendo en corrección y tampoco suele ganarse en propiedad. Muchas veces la claboración del texto consiste en plagiar parcialmente otro anterior, introduciendo las modificaciones o actualizaciones que requiera la circunstancia dentro del párrafo pretérito de lo copiado (1992: 147).

Y, además, continúa diciendo sobre los textos administrativos: «La repetición como norma, el plagio como método, podríamos decir que constituyen el fundamento del discurso administrativo» (1992: 148).

Las formas nominales, verbales y oracionales van entre llaves -\{\} - y precedidas de su nombre correspondiente en mayúscula. Tras él aparece entre corchetes -[ ]- la frecuencia de aparición de toda la estructura. En letra cursiva se ponen de relieve aquellas palabras que se presentan en el texto original.

En la comparación se ha priorizado la intertextualidad, ello no obstante, en algunos casos aparece en una de las descripciones de un dominio un sólo texto porque su estructura es altamente relevante, por ejemplo en «E.4.8. Detención de los miembros del Consejo de Gobierno». La elisión de zonas de texto no significativas para el desarrollo se señalan con tres puntos suspensivos entre paréntesis. 
En la mayoría de las ocasiones se producen alternancias de formas de una misma categoría, por ejemplo: «Asamblea Regional» y «Cortes Generales»; en estos casos se incluye el signo «+» y el nombre de la forma con la inicial «f.»; y, a continuación, se vuelve a incorporar el signo «t». En el caso de variaciones en las formas preposicionales, se incorpora entre cursiva las variantes: $\{$ Derecho $+f$. preposicional: $a[4] / d e[2]+$ transitar $[$ [6]. Si la variantes se producen entre categorías, se escriben separadas también por una barra oblicua; en el ejemplo se ve cómo la barra separa dos formas distintas, una verbal y la otra compuesta por una forma determinativa y nominal, por ejemplo: ORACIONAL $\{\mathrm{F}$. determinativa $+\mathrm{f}$. nominal $/ \mathrm{Se}$ + incluirán la totalidad de los gastos $e$ ingresos de $+\mathrm{f}$. determinativa $+\mathrm{f}$. nominal + f. verbal: consignar: se + futuro/gerundio + el importe de los beneficios fiscales que afecten a tributos\} [2]

Observamos que se hallan variaciones en las unidades léxicas en tanto que unidades semánticas estables, lo generalizado son las variaciones de género, número y tiempo y modo verbal; estas variaciones no suponen ningún problema porque aparecen como formas del mismo lema; en cambio, si las variaciones se producen entre lexías, se tendría que hablar, siendo rigurosos, de otra lexía; esa variación puede ser de la lexía en su totalidad o de una unidad dentro de la propia lexía, ésta última posibilidad es muy frecuente, pero conservaría la estructura morfosintáctica, por ejemplo, en el caso de una forma oracional se representaría como sc muestra en el ejemplo de más abajo; lo mismo ocurre con las formas que hemos liamado nominales, adjetivales y verbales. En estos casos hablaríamos de lexías variables (Pottier 1976: 327).

ORACIONAL $\{$ La + I. nominal + es inviolable $\}[2]$

EA: 21: La Asamblea Regional es inviolable.

ES: 66: Las Cortes Generales son inviolables.

Y, por último, también se produce la variación total de las lexías, formando un grupo unitario, que se van separando de forma clarificadora.

Cuando las variaciones se producen en las formas verbales se resuelven de dos formas, según pertenezcan a un mismo verbo o a verbos distintos. En el primer caso, se redacta de la siguiente forma: se pone la forma en infinitivo junto con los tiempos verbales separados por una barra, véase el caso del dominio «E.2.8.1. Pleno y comisiones»:

ORACIONAL $\{\mathrm{La}+\mathrm{l}$. nominal + $\mathrm{f}$. verbal: funcionar: presente/futuro + en pleno $y+[$. preposicional: en/por + comisiones $\}$ [2]

EA: 28: La Asamblea Regional funciona en pleno y en comisiones.

ES: 75: Las Cámaras funcionarán en Pleno y por Comisiones. 
En el segundo caso, es decir, con verbos distintos, que se presenta de forma reiterada a lo largo de todo el desarrollo, la estructura es similar, por ejemplo: ORACIONAL $\{E l$ Estado + f. verbal: presente/futuro $\}[2]\{L a$ ley + f. verbal: presente[2]/futuro[2]\}[4]. En la segunda estructura oracional la forma en presente y cn futuro aparece dos veces y su frecuencia absoluta se coloca entre paréntesis, y la frecuencia de la totalidad, como se dijo anteriormente, después del paréntesis. Mención especial merecen las estructuras en voz pasiva, que aunque escasas, tienen siempre su correlato en otro fragmento textual en forma activa, por ejemplo: «G.5.3. «Plazo de presentación». Cuando un tiempo verbal aparece en modo indicativo no se especifica tal condición, sólo se indica si aparece alternando con un tiempo en subjuntivo, cn cambio, sí se señala si el modo del tiempo es subjuntivo.

Una forma puede incluirse en otra, por ejemplo, en las verbales:»\{Presente: indicativo[13]/subjuntivo[1]\}[14]» está incluida la forma «\{Integran\}[2]», que aparece en la descripción verbal en orden decreciente de frecuencia (B.1. Derecho a la autonomía, ctc.»)

Puede ocurrir que una forma nominal esté adjetivada, si es así se coloca en letra superíndicc: $\left\langle\mathrm{F}\right.$. nominal ${ }^{\mathrm{A}} \gg$ y si es una forma adjetival la que aparece sustantivada: $\left\langle\mathrm{F}\right.$. adjetival $\left.{ }^{\S}\right\rangle$. No se ha establecido diferenciación formal entre adjetivos calificativos o determinativos a la hora de reflejar su sustantivación.

Conforme se vayan precisando explicaciones en el desarrollo, que presentamos a continuaciôn, se insertarán en nota a pie de página.

\section{A. FÓRMULA PROMULGATORIA (EA; CE)}

ORACIONALIDON JUAN CARLOS I, REY DE ESPAÑA, a todos los que la presente vieren y entendieren, sabed: que las Cortes han aprobado $y+\mathrm{f}$. oracional/f. nominal $+\mathrm{f}$, verbal: participio + la siguiente + [i. nominal $\}[2]$

\section{B. PREÁMBULO}

B.1. Derecho de autonomía. Constitución en Comunidad Autónoma. Estatuto. Valores de la vida colectiva (EA: Preámbulo; CE: Preámbulo, 2, J43, 147)

NOMINAL\{La Constitución $\}[5]$ \{F. nominal + comuin $\}[4]$ \{La Región\}[3] \{Vida\}[3] \{Comunidad Autónoma $\}[3]$ [El derecho a la autonomia $\}[3]$ [Su voluntad $\}[3]$ \{Características $+\mathrm{f}$. adjetival + comunes $\}[3]$ [Entidad + . adjetival $\}[3]$ [F. nominal + histórica $\}[3]$ \{Los Estatutos $\}[2]$ [La justicia $\}[2]$ \{La libertad\}[2] \{Progreso\}[2] \{Las provincias\}[2] \{Entidad histórica\}[2] \{La Nación española\}[2] \{Uma digna calidad de vida\}[2] \{Noma institucional básica\}[2] \{La Región de Murcia\}[2] \{El articulo $+[$ adjotival + de la Constitución $\}[2]\{$ El derecho a la autonomía de las $+f$. nominal $\}[2]\{E I$ presente $+f$. nominal $\}[2]$ \{Las decisiones de $+\mathrm{f}$. determinativa $+\mathrm{f}$. nominal $\}[2]\{$ El progreso de la $+\mathrm{f}$. nominal $\} \mid 2]\{U s o d e+[$. nominal $\}[2]\{\mathrm{F}$. nominal + regional $\}[2]$ [F. nominal + del derecho a la a

VERBAL\{Presente: indicativo[13\}/subjuntivo[1]\}[14] \{Infinitivo\}[7] \{Futuro\}[5] \{Participio\}[5] \{Asegurar: presente subjuntivo: asegure[1]/infinitivo: asegurar[1]\}[2] \{Integran\}[2] \{Manifiesta\}[2] $\{$ Prockamar\}[2] \{Reconoce\}[2] \{Ser: presente: es[1]/futuro: serán[1]\}[2] \{Podrán + infinitivo\}[2] \{Gerundio\}[2] \{Constituirse\}[2] \{Promover\}[2]

ORACIONAL $[L t+f$. nominal + f. verbal: gerundio + f. nominal/f, verbal: infinitivo $\}[2]\{L a+f$. nominal + f. verbal: presente + su voluntad de + f. verbal: infinitivo $\}[2]$ \{El Estatuto + f. verbal: ser: presente/futuro + la norma instifucional básica $\}[2]\{\mathrm{F}$. determinativa $+\mathrm{f}$. nominal + proclama $+[\ldots]+$ 
la liberad, la justicia y la $+\int$. nominal\}[2] \{Constituirse en Comunidad Autónoma $\}[2]\{\mathrm{F}$. verbal + derecho a la autonomía\} [2] \{La Región de Murcia manifiesta su voluntad de $+\int$, verbal: infinitivo\} [2] B.2. Estatuto. Principio de solidaridad. Unidad de España (EA: Preámbulo; CE: 2, 138)

NOMINAL $\{$ La solidaridad $\}[3]\{$ La Constitución $\}[2]$ [El principio de solidaridad $\}[2]$ \{ La unidad de + f. nominal $\{[2]\{$ F. nominal $+e s p a n ̃ o l\}[2]$

VERBAL\{Presente\}[6] \{Garantiza\}[2] \{Gerundio\}[2] \{Participio\}[2]

ORACIONAL $\{\mathrm{F}$. determinativa + f. nominal + $\mathrm{f}$. verbal: presente + el principio de solidaridad $\}[2]\{\mathrm{F}$. verbal + la unidad de + f. nominal $\}[2]$

B.3. Desarrollo de las comarcas de la Región (EA: Preámbulo; CE: 158)

NOMINAL $\{$ Desequilibrios $+f$. nominal $+\mathrm{f}$. adjetival $\}[2]$

VERBAL\{Futuro\}[3] \{ Infinitivo\} [3]

ORACIONAL $\{\mathrm{F}$. verbal: infinitivo + desequilibrios $+\mathrm{f}$. adjetival $\}[2]$

B.4. Proposición y aprobación del Estatuto (EA: Préínbulo; CE: Prémbulo, 146)

NOMINAL\{Las Contes\}[3] \{Asamblea\}[2] \{Constitución\}[2] \{Diputados\}[2] \{Estaluto\}[2] \{Las Cortes Generales\}[2] \{La Región de Murcia\}[2]

VERBAL\{Participio\}[6] \{Presente\}[4] \{Aprueban\}[2] \{Será + participio\}[2]

ORACIONAL $\{$ Las Cortes aprueban $+\mathrm{f}$. determinativa $+\mathrm{f}$. adjetival $+\mathrm{f}$. nominal $\}[2]$

C. TÍTULO PRELIMINAR

C. 1. Constitución en Comunidad Autónoma y autogobierno (EA: Preámbulo, 1; CE: 2, 143, 148)

NOMINAL $\{$ La Constitución\}[6] \{Estatuto\}[4] \{Comunidad Autónoma\}[4] \{F. nominal + común\}[4] $\{$ La provincia\} $\}[3]$ \{Entidad histórica $\}[3]$ \{Noma institucional básica $\}\{3]\{$ Presente $+\mathrm{f}$. nominal\}[3] $\{$ F. adjetival + Estatuto $\}[3]\{$ Espoña $\}[2]\{$ Caracteristicas + f. adjetival + comtntes $\}[3]\{$ Región $\}[2]\{$ Su aunogobiemo\}[2] \{El presente Estatuto\}[2] \{Entidad regional histórica $\}[2]$ [La indisoluble unidad de + I. nominal $\}[2]$ [El derecho a la cautonomia de las $+\mathrm{f}$. nominal $\}[2]\{$ Patria $+\mathrm{f}$. adjetival $\}[2]\{$ La $+\mathrm{f}$. nominal + de Murcia $\}[2]\{$ El articulo $+f$. adjetival + de la Constitución $\}[2]\{\mathrm{F}$. nominal + del derecho ala antonomía $\}[2]\{[$. nominal + histórica $\}[2]$

VERBAL $\{$ Presente $\}[8] \quad\{$ Participio $\}[5] \quad\{$ Reconocer: presente: reconoce [2]/futuro: reconoceril 1]/participio: reconocido[1]\}[4] [Ser: presente: es[2]/futuro: serin[1]\}[3] \{Constituirse: presente: se constituye[1]/infinitivo: constituirse [2]\}[3] \{Acceder $\}[2]\{$ Se + presente $\}[2]\{$ Futuro $\}[2]$

ORACIONAL[La + f, nominal + de Murcia, entidad histórica + [...] + f. verbal: se constimyelmanifiesia su voluntad de constituirse + en Comunidad Autónoma, de acuerdo con la Constitución y el presente Estatuto, que es su norma institucional básica $][2][\mathrm{F}$. determinativa $+\mathrm{r}$. nominal $+[\ldots]+$ entidad regional histórica $+\mathrm{f}$. verbal: infinitivo/futuro: acceder/podrán acceder + a su autogobiemo\}[2] \{La Constiución reconoce el derecho a la autonomia $\}[2]$ [El Estatuto es $+\mathrm{C}$. determinativat + norma institucional básica $][3]$

C.2. Denominación de la Comunidad (EA: $l ; \mathrm{CE}:$ 147)

NOMINAL\{La Comunidad $\}[2]$

VERBAL\{Presente: indicativo[1]/subjuntivo[1]\}[2]

C.3. Origen de los poderes (EA: $2 ; \mathrm{CE}: 1$ )

NOMINAL $\{$ El pueble $\}[2]$ \{Los poderes de $+f$. determinativa $+f$. nominal $\}[2]$

VERBAL\{Presente\}[3] \{Emanam $\}[2]$

ORACIONAL $\{$ Los poderes de + f. nominal + emanan del pueblo\}[2]

C.4. División político-administrativa del territorio (EA: 3; CE: 137, 140, 141, 147, 152)

NOMINAL\{Municipios\}[10] \{Autonomia $\}[4] \quad\{L a$ provincia $\}[4]$ [Enidades\}[3] $\{$ La Comunidad Autónoma $\}[3]\{\mathrm{F}$. nominal + territorial $\}[3]\{$ Comarcas $\}[2]\{$ El Estado\}[2] \{Los Estatutos\}[2] $\{$ La ley\}[2] \{Territorio\}[2] \{La agrupación de municipios\}[2] \{El cumplimiento de los $+\mathrm{f}$. nominal\}[2] \{La gestión de $+f$. determinativa + intereses $\}[2]\{$ La gestión de $+f$. nominal $+\mathrm{f}$. adjetival $\}[2]$ $\{$ Personalidad juridica + f. adjetival $\}[2]\{$ F. nominal + de Murcia $\}[2]\{$ F. nominal + propia $\}[2]$

VERBAL\{Presente: indicativo[9]/subjuntivo[2]\}[11] \{Futuro\}[8] \{Infinitivo\}[6] \{Gozar: presente: gozan[3] /fukuro: gozarám[2]\}[5] \{Se + presente[1]/futuro[3]\}[4] $\{$ Se podrán + infinitivo\}[4] \{Ser: 
presente: es[2], son[1]\}[3] \{Participio\}[3] \{Se organiza\}[2] \{Se podrán crear\}[2] \{Podrán + infinitivo $\}[2]$

ORACIONAL $\{\mathrm{F}$. determinativa $+\mathrm{f}$. nominal + se organiza territorialmente en municipios $y+f$. nominal $\}[2]\{\mathrm{F}$. determinativa $+\mathrm{f}$. nominal + gozan de autonomía para la gestión de sus intereses $\}[2]$ $\{\mathrm{F}$. determinativa $+\mathrm{f}$. nominal + gozan de autonomía para $+\mathrm{f}$. determinativa $+\mathrm{f}$. nominal $\}[3]\{\mathrm{F}$. determinativa $+f$. nominal + gozan de plena personalidad jurídica y/de autonomía $\}[2]$ [Los mumicipios/f. pronombre + f. verbal: gozar: presente/futuro + de plena personalidad jurídica\}[2] $\{\mathrm{F}$. pronombre + gozarán de plena personalidad juridica $\}[2]\{\mathrm{F}$. determinativa $+\mathrm{f}$. nominal[2]/f. pronombre[2] + [. verbal: gozar: presente[2]/futuro[2] + de plena personalidad jurídica $\}[4]$ [Se podrán crear $+f$. nominal $\}[2]$

C.5. Símbolos de la Comunidad (EA: 4; CE: 4)

NOMINAL $\{$ Bandera $\}[5]\{$ La bandera de $+\mathrm{f}$. nominal $\}[3]\{$ Fondo rojo $+\mathrm{f}$. adjetival $\}[3]$ TTres franjas horizontales $+\mathrm{f}$. adjetival $\}[3]$ \{La bandera de España $\}[2]\{$ La Conunidad Autónona $\}[2]\{$ El ángulo + [. adjetival $+f$, adjetival $\}[2]$

VERBAL\{Futuro\}[5] \{Participio\}[4] \{Presente\}[3] \{Tendrá\}[2]

ORACIONAL $\{$ La bandera de $+f$. nominal $+f$. verbal: presente $\}[2]\{F$. determinativa $+f$. nominal + tendrá + . nominal\} $[2]$

C.6. Capital y sede de los órganos institucionales (EA: 5; CE: 147)

NOMINAL $\{$ Ciudad $\}[2]$ \{Sede de $+\mathrm{f}$. determinativa $+\mathrm{f}$. nominal $+\mathrm{f}$. adjetival $\}[2]$

VERBAL\{Futuro\}[3]

ORACIONAL $\{\mathrm{F}$. verbal + sede de $+\mathrm{f}$. determinativa $+f$, nominal $+f$. adjetival $\}[2]\{F$. verbal: presente/futuro + en la ciudad de $+\mathrm{f}$. nominal $\}[2]$

C.7. Condición política de murciano (EA: 6$)$

NOMINAL\{Condición\}[4] \{Los españoles\}[3] \{Estatuto\}[2] \{La Región\}[2] \{F. determinativa + condición ] [2]

VERBAL\{Presente: indicativo[2]/subjuntivo[3]\}[5] \{Gozar: presente: gozan[1]/ futuro: gozarán[2]\}[3] $\{$ Participio\}[3]

ORACIONAL $\{$ Los españoles + f. verbal: gozar: presente/futuro + de la condición + f. adjetival $\}$ [2] $\{$ Gozarain de $+f$. adjetiva + condición $\}[2]$

C.8. Emigrantes (EA: 7; CE: 42, 68)

NOMINAL $\{$ Derecho $\}[4]\{$ El Estado $\}[4]\{$ Ley $\}[3]\{L a+f$. nominal + de los derechos $+\mathrm{f}$. adjetival $\}[3]$ $\{$ La Región\}[2] \{Derecho $a+$ infinitivo\}[2] \{Leyes de $+\mathrm{f}$. determinativa $+\mathrm{f}$. nominal\}[2] \{Los derechos $+f$. adjetival + de los trabajadores españoles $\}[2]\{L a$ vida $+f$. adjetival $\}[2]\{$ Las $+f$. nominal + del Estado $\}[2]\{$ F. nominal + social $\}[2]$

VERBAL\{Futuro\} [8] \{Infinitivo\}[3] \{Participio\}[3]

ORACIONAL\{F. determinativa + ley + f. verbal: futuro\}[2] $\{$ El Estado + f. verbal: futuro $\}[2]$

C.9. Derecho consuletudinario (EA: 8; CE: 125)

NOMINAL $\{\mathrm{F}$. nominal + consuetudinario $\}[3]$ [F. nominal + popular $\}[3]$ \{Los tribunales consuetudinarios y tradicionales $\}[2]$ \{El acervo de $+\mathrm{f}$. nominal + populares $\}[2]$ [Las variantes $+\mathrm{f}$. adjetival\}[2]

VERBAL\{Futuro\}[5] \{Podrán + infinitivo\}[2]

C. 10. Igualdad de derechos en todo el territorio (EA: 9; CE: 139)

NOMINAL $\{$ Los españoles $\}[2]$ [Los derechos $\mathrm{y}+\mathrm{f}$. nominal $\}[2]\{L o s+\mathrm{f}$. nominal + fundamentales de los murcianos $][2]$

VERBAL $\{$ Presente $\}[2]$

C.I I. Competencias de la Comunidad Autónoma en materia de derechos y deberes

C.1 I.I. Ejercicio de los derechos y observancia de los deberes (EA: 9; CE: 149)

NOMINAL $\{E l$ ejercicio de los derechos\}[2] \{El adecuado ejercicio de los $+\mathrm{f}$. nominal $+\mathrm{f}$. adjetival $\}[2]\{F$. nominal + de $+f$. determinativa + deberes $\}[2]\{$ Competencia $\}[2]$ 
VERBAL\{Garantizar: presente subjuntivo: garanticen[1]/infinitivo[1]\}[2] \{Presente: indicativo[!]/subjuntivo[1]\}[2]

ORACIONAL $\{F$. verbal: garantizar: infinitivo/presente subjuntivo $+[\ldots]+$ ejercicio de los derechos + $[\ldots]+f$. determinativa $+\mathrm{f}$. nominal + de $+\mathrm{f}$. determinativa + deberes $][2]$

C.11.2. Deber y obligación de la Comunidad (EA: 9; CE: 9)

ORACIONAL Promover las condiciones para que la libertad y la igualdad del individuo y de los grupos en que se integra sean efectivas y reales, + $\mathrm{f}$. verbal: remover: gerundio/infinitivo + los obsticuluos gue impidan o dificulten su plenitud\}[2]

C.11.3. Fonento de la cultura (EA: 9; CE: 148)

NOMINAL $\{$ Competencia $\}[2]$

ORACIONAL\{La Comunidad Autónoma $+[\ldots]+$ competencia $+\mathrm{f}$. verbal: futuro + el desarrollo culiural] [2]

C. 1 í.4. Calidad de vida (EA: 9; CE: 45)

ORACIONAL $\{\mathrm{F}$. determinativa + f. nominal + velará por mejorar la calidad de vida $\}[2]$

C. 1 1.5. Principios del régimen económico (EA: 9; CE: 40)

NOMINAL $\{$ F. nominal + económico\}][3] [El progreso económico y social\}[2] \{Una distribución de la renta $+f$, adjetival + mas equitativa $\}[2]$

VERBAL\{Promover: presente subjuntivo: promuevan[1]/futuro: pronoverán[2]\}[2] \{Presente subjuntivo\}\{2] \{Futuro\}[2]

ORACIONAL $\{\mathrm{F}$. determinativa + f. nominal/f, pronombre $+f$. verbal: promover: presente subjuntivo/futuro $+[\ldots]+$ el progreso económico y social $][2]$

C.11.6. Pleno empleo (EA: 9; CE: 40)

NOMINAL $\{$ El empleo $\}[2]$ \{El progreso $+f$, adjetival $\}[2]$

VERBAL\{Presente subjuntivo] [2] \{Futuro\}[2]

C.11.7. Finalidad y obligación suprema de la Comunidad (EA: 9; CE: 9)

ORACIONAL $\{\mathrm{F}$. determinativa + f. nominal + f. verbal: presente/futuro + facilitar la participación de todos $l o s+f$. adjetival ${ }^{s}+$ en la vida política, económica, cultural y social $\}[2]$

C.I1 8. Solidaridad entre los municipios (EA: 9; CE: 2, 138)

NOMINAL $\{$ La Consititución $\}[3]\{$ La Comunidad Autónoma $\}[2]$ \{Solidaridad $\}[2]$ \{Establecimiento de an equilibrio económico $+\mathrm{f}$. adjetival $\}[2]\{$ Patria $+\mathrm{f}$. adjetival + de todos los españoles $\}[2]\{E t$ derecho a la autonomía de las + nominal $\}[2]$

VERBAL\{Presente\}[4] \{Gerundio\}[3] \{Garantiza\}[2]

ORACIONAL $\{\mathrm{F}$. determinativa $+\mathrm{f}$. nominal + garantiza $+[\ldots]+$ solidaridad $\}[2]\{\mathrm{F}$. verbal: infinitivo/presente + la solidaridad entre $+[\ldots]\}[2]$

D. TÍTULO I: DE LAS COMPETENCIAS DE LA COMUNIDAD AUTÓNOMA DE LA REGIÓN DE MURCIA

D.1. Competencias exclusivas. (EA: 10; CE: 149, 148)

NOMINAL $\{$ La Comunidad Autónoma $\}[2]$

VERBAL\{Presente\}[2]

ORACIONAL\{F. verbal: presente + competenciat exclusiva +f. preposicional: en/sobre + las siguientes materias $\}[2]$ [F. determinativa $+\mathrm{f}$. nominal + verbal: presente/futuro + competencia en las siguientes materias $\}[2]\{\mathrm{F}$. verbal + competencia $+\mathrm{f}$. preposicional: en[2]/sobre[1]+las siguientes materias $\}[3]$

D.1.1. Funcionamiento de las Instituciones de autogobierno y administración

D.1.1.1. Organización, régimen jurídico y funcionamiento de instituciones (EA: 10; CE: 148)

NOMINAL $\{$ La Comunidad Autónoma $\}[2]$

VERBAL\{Presente\} [2]

ORACIONAL $\{\mathrm{F}$. verbal: presente/futuro + competencia en las siguientes materias: Organización de sus instituciones de autogobierno\}[2]

D.1.1.2. Procedimicnto administrativo propio (EA: 10; CE: 149) 
ORACIONAL $\{\mathrm{F}$, verbal: presente + competencia exclusiva $+\mathrm{f}$. preposicional: en/sobre + las siguientes materias: Procedimiento administrativo derivado de las especialidades de la organización previa\}[2]

D.1.2. Desarrollo y asistencia sociales

D.1.2.1. Asistencia y bienestar social (EA: 10; CE: 4l, 148)

NOMINAL $\{\mathrm{F}$. nominal + social $\}[4]\{\mathrm{F}$. nominal $+y+\mathrm{f}$. nominal + social $\}[4]\{$ Asistencia social $\}[3]$

\{Competencia\}[2] [La Comunidad Autónoma\}[2] \{Las siguientes materias\}[2] \{F. nominal + sociales

suficientes\}[2]

VERBAL $\{$ Futuro\}[2] \{Presente: indicativo[1]/subjuntivo[1]\}[2]

ORACIONAL $\{\mathrm{F}$. verbal: presente/futuro + competencia en las siguientes materias: Asistencia social\}|2!

D.I.2.2. Política infantil. Instituciones de protección y tutela de menores (EA; 10; CE: 39)

NOMINAL\{La ley\}[2] \{Menores\}[2] $\{L a$ protección $\}[3] \quad\{L a$ legislación $+\mathbf{f}$ adjetival\}[3] $\{$ Instituciones de $+\mathrm{f}$. nominal + de menores $\}[2]\{$ La protección $+\mathrm{f}$. adjetival $\}[2]\{\mathrm{F}$. nominal + (ivil\}|2]

VERBAL $\{$ Presente: indicativo[3]/subjuntivo[1]\}[4] \{Futuro\}[2]

ORACIONAL $\{\mathrm{F}$. determinativa $+\mathrm{f}$. nominal $+\mathrm{f}$, verbal: presente/futuro + la protección $\}[2]$

D.1.2.3. Política de la tercera edad (EA: 10; CE: 50)

NOMINAL $\{$ Sis problemas expecificos de $+\mathrm{f}$. nominal\}[4] $\{$ Pensiones $+\mathrm{f}$. adjetival $\}[2]\{$ Política $+\mathrm{f}$. adjetival $\}[2]\{$ F. nominal + de la tercera edad $\}[2]$

VERBAL\{Fuluro\}[3] \{Participio\}[2]

ORACIONAL $\{$ Los poleres públicos $+\mathrm{f}$. verbal: futuro + mediante $+\mathrm{f}$. nominal $\}[2]$

D.1 2.4. Promoción e integración de los discapacitados (EA: 10; CE: 49)

NOMINAL $\{$ La creación de centros de $+\mathrm{f}$. nominal\}[3] $\{$ Una política de $+\mathrm{f}$. nominal + de los aisminuides $+f$. adjetival $\}[3]\{$ Protección $\}[2]\left\{\right.$ Integración de los $+\mathrm{f}$. adjetival $\left.{ }^{\mathrm{S}}\right\}[2]\{\mathrm{F}$. nominal + de relabilitación $][2]\{\mathrm{F}$. nominal + de los discapacitados $\}[2]$

VERBAL\{Futuro\}[3] \{Presente\}[2]

ORACIONAL $\{$ Los poderes públicos $+f$. verbal: futuro $\}[3]$

D.1.2.5. Promoción e integración de los emigrantes y demás grupos sociales (EA: 10; CE: 149)

NOMINAL $\{\mathrm{F}$. nominal + de los emigrantes y demús grupos sociales $\}[2]$

VERBAL[Presente][2]

ORACIONAL $\{\mathrm{F}$, verbal + conpetencia exclusiva $+\mathrm{f}$. preposicional: en/sobre + las siguientes materias:

$+[\ldots]\}[2]$

D.1.2.6. Creación de centros de protección, reinserción y rehabilitación (EA: 10; CE: 49)

NOMINAL $\{$ la creación de centros de $+\mathrm{f}$. nominal\}[3] \{Una politica de $+\mathrm{f}$. nominal + de los disminuidos $+[$ adjelival $\}[3]$ \{Protección $\}[2]$ \{ Integración de los $+f$ adjetival $\left.{ }^{s}\right\}[2]\{\mathrm{F}$. nominal + de rehabilitación $][2]$ [F. nominal + de los discapacitados $\}[2]$

VERBAL\{ Futuro\}[3] \{Presente\}[2]

ORACIONAL $\{$ Los poderes públicos $+f$, verbal: futuro $\}[3]$

D.1.2.7. Política juvenil (EA: 10; CE: 48)

NOMINAL $\{$ EI desarrollo $+f$. adjetival\} [4] \{La participación $+\mathrm{f}$. adjetival + de la juventud $\}[2]$

D.1.2.8. Promoción de la mujer (EA: 10; CE: 39)

VERBAL[Presente: indicativo[2]/subjuntivo[1]\}[3]

D.I.3. Educación y cultura

D.1.3.1. Artesanía (EA: 10; CE: 130, 148)

NOMINAL\{Artescmia\}[3] \{La Comunidad Autónoma\}[2] \{Competencia en las siguientes materias\}[2]

$[$ l.a $+\mathrm{f}$. nominal + de lodos los sectores económicos $\}[2]$ [Los sectores de la $+\mathrm{f}$. nominal $\}[4]$

VERBAL\{Futwo $\}[2]$ \{ Infinitivo $\}[2]$

ORACIONAL $\{\mathrm{F}$. verbal: presente/futuro + competencia en las siguientes materias: Artesania $\}[2]$

D. 1,3.2. Museos, archivos, bibliotecas, hemerotecas, etc. (EA: I0, 12; CE: 148)

NOMINAL $\{$ La Comunidad Autónoma $\}[3]$ 
ORACIONAL\{F. verbal: presente/futuro + competencia en las siguientes materias: Museos, bibliotecas, conservatorios de música de interés para la $+\mathrm{f}$. nominal\}[2] \{Corresponde a la $+\mathrm{f}$. nominal + las siguientes materias: museos, archivos, bibliotecas de interés de titularidad estatal que no +f. verbal: presente: subjuntivo [ [2]

D.1.3.3. Patrimonio cultural, histórico, arqueológico, etc. (EA: 10; CE: 46, 148, 149)

NOMINAL $\{$ La Comunidades Autónoma\}[4] \{Defensa del patrimonio + . adjetival + español $\}[3]\{E l$ enriquecimiento del patrimonio $+\mathrm{f}$. adjetival + de los pueblos de España\}[3] [Titularidad\}[2] \{Patrimonio monumental de interés\}[2] \{Competencia en las siguientes materias\}[2] \{Competencia exclusiva $+\mathrm{f}$. preposicional + las siguientes materias\}[2] \{Patrimonio histórico, cultural y artístico de + f. nominal $\}[2]$

VERBAL\{Futuro\}[3] \{Presente: indicativo[3]/subjuntivo[1]\}[4]

ORACIONAL $\{\mathrm{F}$. verbal: presente/futuro + competencia en las siguientes materias: patrimonio monumental de interés $+f$. preposicional: paralde $+l a+f$. nominal $\}[2]\{F$. verbal + competencia exclusiva +8 preposicional: en/sobre + las siguientes materias: Patrimonio cultural, histórico y artístico $\}[2]\{\mathrm{F}$. verbal + competencia $+\mathrm{f}$. preposicional: en $[2] /$ sobre $[1]+$ las siguientes materias: Patrinomio\} $[3]$ \{Los poderes piblicos $+\mathrm{f}$. verbal: futuro $+\mathrm{f}$. determinativa $+\mathrm{f}$. nominal $\}[2]$

D.1.3.4. Fomento de la cultura y de la investigación científica (EA: 10; CE: 44, 148, 149)

NOMINAL $\{$ Fomento de la $+\mathrm{f}$. nominal $\}[7]$ \{Cultura $\}$ [3] \{La Comunidad Autónoma\} [3] \{Fomento de la investigación $\}[3]$ \{La investigación científica y técnica $\}[3]$ [F. nominal + de la investigación cientifica y técnica\}[3] \{Coordinación\}[2] \{El Estado\}[2] \{Los poderes públicos\}[2] \{Fomento de la cultura\}[2] \{Fomento de la investigación científica y técnica\}[2] \{Competencia en las siguientes muterias $\}[2]\{$ Competencia exclusiva $+\mathrm{f}$. preposicional + las siguientes materias $\}[2]\{$ La $+\mathrm{f}$. nominal + de Murcia $\}[2]$

VERBAL\{Futuro\}[4] \{Presente\}[3] \{Promoverán\}[2] \{Tener: presente: tiene[1]/ tienen[1]\}[2]

ORACIONAL\{F. verbal: presente/futuro + competencia en las siguientes materias: fomento de la cultura y de la investigación $\}[2]$ \{F. verbal + competencia exclusiva + f. preposicional: en/sobre + las siguientes materias: Fomento de la investigación cientifica y técnica $\}[2]\{\mathrm{F}$. verbal + contpetencia $+\mathrm{f}$. preposicional: en[2]/sobre[1] + las siguientes materias: Fomento de la investigación\}[3] \{Los poderes públicos promoverán $+\mathrm{f}$. determinativa $+\mathrm{f}$. nominal $\}[2]$

D. 1.3.5. Promoción fomento y ordenación del turismo (EA: 10; CE: 148)

NOMINAL $\{$ La Comunidad Autónonta $\}[2]$

ORACIONAL $\{\mathrm{F}$. verbal: presente/futuro + competencia en las siguientes materias: Promoción y ordenación del turismo en su ámbito [2]

D.1.3.6. Promoción del deporte y de la utilización del ocio (EA: 10; CE: 43, 148)

NOMINAL\{La adecuada utilización del ocio\}][3] \{El deporte\}[2] [Comunidad Autónoma\}[2]

VERBAL\{Presente\}[I] \{Futuro\}[3]

ORACIONAL $\{\mathrm{F}$. verbal: presente/futuro + competencia en las siguientes materias Promoción del deporte y de la aulecuada utilización del ocio][2]

D.1.3.7. Fundaciones (EA: 10; CE: 34)

NOMINAL\{Fundación $\}[3]\{$ La Comunidad Autónoma $\}[2]$

VERBAL\{Presente: indicativo[3]/subjuntivo[1]\}[4]

D.1.3.8. Potestades y competencias en medios audiovisuales (EA: 11, 14; CE: 20, 149)

NOMINAL $\{$ El Estado\}[5] \{Medios de comunicación social\}[4] \{La Comunidad Autónoma $\}[3]$ $\{$ Normas básicas del régimen de $+\mathrm{f}$. nominal\}[3] $\{\mathrm{F}$. nominal + básica\}[3] \{Caso\}[2] $\{$ Competencia\}[2] \{Desarrollo\}[2] \{Ejecución\}[2] \{Prensa\}[2] \{Radio\}[2] \{Televisión $\}[2]\{$ La ley\}[2] \{Normas básicas\}[2] \{Las siguientes materias\}[2] \{En el marco de la $+\mathrm{f}$. nominal + básica $\}[2]$ \{Los grupos $+\mathrm{f}$. adjetival + significativos $\}[2]$ [F. nominal + de los medios de comunicación social dependientes del Estado\}[2]

VERBAL\{Presente: indicativo[2]/subjuntivo[4]\}[6] \{Futuro\}[3] \{Correspondan $\}[2]\{$ Establezca\}[2] 
ORACIONAL\{F. verbal: presente + f. preposicional: en/sobre + las siguientes materias: prensa, radio, selevisión $y+\mathrm{f}$. determinativa + medios de comunicación social $\}[2]\{$ La ley $+\mathrm{f}$. verbal: futuro $+\mathrm{f}$. deteminativa $+f$, nominal $\}[2]\{$ En el marco de la + f. nominal + básica + que establezca $\}[2]$

D.1.4. Vías de comunicación y transporte

D. 1,4.1. Ferrocarriles, carreteras y caminos (EA: 10; CE: 148, 149)

ORACIONAL $\{\mathrm{F}$. verbal: presente/futuro + competencia en las siguientes materias: Los ferrocarriles $y$ carreteras cuyo itinerario $+\mathrm{f}$. verbal: presente subjuntivo + integramente en el territorio de la Comunidad Autónoma y, en los mismos términos, el transporte desarrollado por estos medios, por cable $\}[2]\{\mathrm{F}$. verbal + competencia exclusiva $+\mathrm{f}$. preposicional: en/sobre + las siguientes materias: ferrocirriles y transporte $+\mathrm{f}$, verbal: presente subjuntivo $+\mathrm{f}$. preposicional: en/por + el territorio\}[2] $\{F$. verbal + competencia $+f$. preposicional: en $[2] /$ sobre $[1]+$ las siguientes materias: Ferrocarriles $y$ tramsporte $+f$, verbal: presente subjuntivo $+f$. preposicional: en [2]/por $[1]+$ el ferritorio\}[3]

D. I.4.1. Transporte marítimo y aéreo (EA: 10; CE: 148, 149)

NOMINAL\{Puertos\}[6] \{Aeropuertos\}[3] \{Transporte $\}[3]$ \{La Comunidad Autónoma $\}[3]$ [F. nominal + déreo $\}[3]\{\mathrm{F}$. nominal + de interés general $\}[3]$ [Competencia en las siguientes materias $\}[2]\{$ Puertos o puntos de $+f$. determinativa $+\mathrm{f}$. nominal $\}[2]$ \{Competencia exclusiva $+\mathrm{f}$. preposicional + las siguientes materias\}[2] \{Transporte $+\mathrm{f}$. adjetiva $\}[2]\{\mathrm{F}$. nominal + de la Comunidad Autónoma $\}[2]\{\mathrm{F}$. nominal + deportivos $][2]$

VERBAL\{Prcsentc: indicativo[2]/subjuntivo[2]\}[4] (Tener: presente: indicativo: tiene[1]/subjuntivo: tengam[1]\}[2]

ORACIONAL F F. verbal + competencia exclusiva + f. preposicional: en/sobre + las siguientes materias: Puentos, aeropuertos de interés general $\}[2]$ [F. verbal: presente/futuro + competencia en las siguientes materias: puerfos $\}[2]\{\mathrm{F}$. verbal + competencia $+\mathrm{f}$. preposicional: en[2]/sobre[1] + las siguientes materias: puertos $\}[3]$

D. I.5. Utilización y aprovechamiento de recursos naturales

D.1.5.1. Proyectos, construcción y explotación de aprovechamientos hidráulicos, etc. (EA: 10; CE: 148)

ORACIONAL\{F. verbal: presente/futuro + competencia en las siguientes materias proyectos, construcción y explotación de aprovechamientos hidráulicos, canales y regadios de interés $+\mathrm{f}$. preposicional: defpara + la Comunidad Autónoma. Aguas minerales y termales $\}[2]$

D.1.5.2. Ordenación y concesión de recursos y aprovechamientos hidráulicos (EA: 10; CE: 149)

ORACIONAL $[\mathrm{F}$. verbal + competencia exclusiva + f. preposicional: en/sobre + las siguientes materias: Ordencición y concesión de recursos y aprovechamientos hidráulicos, aguas cuando discurran $+\mathrm{f}$. preposicionall: en/por $+f$. nominal/f. adverbial $+d e+f$. determinativa + Comunidad Autónoma $][2]$

D. 1.5.3. Cazal y pesca lluvial y protección de los ecosistemas (EA: 10; CE: 148, 149)

ORACIONAL[F. verbal: presente/futuro + competencia en las siguientes materias Pesca en aguas interiores, marisqueo, acuicultura. Caza y pesca fluvial $\}[2]\{\mathrm{F}$. verbal + competencia exclusiva $+\mathrm{f}$. preposicional: en/sobre + las siguientes materias: Pesca $\}[2]\{\mathrm{F}$. verbal + competencia $+\mathrm{f}$. preposicional: en[2]/sobre[1] + las siguientes materias: Pesca $\}[3]$

D. 1.5.4. Régimen de las zonas de montaña (EA: 10; CE: 130)

NOMINAL\{la + I. nominal + de todos los sectores económicos\}[2] \{Los sectores de la + . nominal $\}[4]$ [Las zonas de montaña $\}[2]$

VERBAL $\{$ Futuro\}[2]

D.1.6. Economía, industria y comercio

D.1.6.1. Agricultura, ganadería e industrias agroalimentarias (EA: 10; CE: 148)

ORACIONAL $\{\mathrm{F}$, verbal: presente/futuro + competencia en las siguientes materias Agricultura, gancideria, de acuerdo con la ordenación general de la economia) [2]

D. 1.6.2. Planilicación, fomento y desarrollo de la actividad económica (EA: 10; CE: 128, 131, 148, 149)

NOMINAL\{F. nominal + económico\}[9] \{La Comunidad Autónoma $\}[6]$ [La actividad económica\}[4] $\{$ Planificación de la actividad económica\}[4] \{Ley\}[3] \{Planificación\}[3] \{Otras organizaciones $+\mathrm{f}$. adjetival\}[3] $\{\mathrm{F}$. nominal + general $\}[3]\{\mathrm{F}$. nominal + público $\}[3]\{$ El Estado $\}[2]\{$ Los objetivos 
marcados\}[2] [Sector público\}[2] \{La política económica nacional\}[2] \{Competencia en las siguientes materiss\}[2] \{Desarollo económico de la Comunidad Autónoma\}[2] \{Fomento econónico de la Comunidad Autónoma\}[2] \{Competencia exclusiva $+\mathrm{f}$. preposicional + las siguientes materias $\}[2]$ $\{$ Crecimiento de la $+\mathrm{f}$. nominal $\}[2]\{$ El desarrollo $+\mathrm{f}$. adjetival $\}[2]\{L a+\mathrm{f}$. nominal + de un sector públices regional propio de la Comunidad Autónoma\} $[2]$ \{F. nominal + esenciales\}[2] [F. nominal + regiomal $\}[2]\{\mathrm{F}$. nominal + de los sindicatos $\}[2]\{\mathrm{F}$. nominal + de la planificación genteral de ia actividad economical $\}$ [2]

VERBAL\{ Infinitivo\}[8] \{Futuro\}[7] $\{$ Se + presente[1]/futuro[4]\}[5] \{Presente: indicativo[3]/subjuntivo[1]]\}[4] \{Podrá + infinitivo $\}[2]$ \{Se podrá + infinitivo $\}[2]$

ORACIONAL\{F, verbal: presente/futuro + competencia en las siguientes materias: fomento $+\mathrm{f}$. relacional/f. preposicional + desarrollo económico de la Comunidad Autónoma dentro de los objetivos marcados por la política económica nacional $\}$ [2] $\{\mathrm{F}$. verbal + competencia exclusiva + f. preposicional: entsobre + las siguientes malerias: planificación de la actividad económica $]$ [2]

D. 1.6.3. Creación y gestión de un sector público regional (EA: 10; CE: 128)

NOMINAL $\{$ La Comunidad Autónoma $\}[3]$ [F. nominal + público\}[3] \{La actividad económica\}[2] \{Sector publico\}[2] $\{\mathrm{F}$. nominal + esenciales\}[2] \{F. nominal + económico de la Comtuidad Autónoma\}\}[2] \{F. nominal + de un sector público regional propio de la Comunidad Autónoma\}[2]

VERBAL\{Se + prescnte[1]/futuro[2]\}[3] \{Presente\}[2] \{Futuro: indicativo[2]/ subjuntivo[1]\}[3] \{Se podrá + infinitivo\}[2]

D.1 6.4. Ejecución cie planes económicos del Estado (EA: 17; CE: 130, 131, 149)

NOMINAL\{F. nominal + económico $\}[5]\{$ Los sectores de la + f. nominal $\}[4]\{L a+[$. nomina + de todos ies sectores ecomónicos\}[2] \{Actividad\}[3] \{Desarrollo\}[2] \{EI Estado\}[3] \{Ley\}[2] \{La Regicin\} $\{2\}$ \{La actividad econónica\} [2] \{Sectores económicos\}[2] \{Desarrollo $+\mathrm{f}$. adjetival\}[2] [F. nominal + general $\}[2]\{\mathrm{F}$. nominal + puiblico $\}[2]\{\mathrm{F}$. nominal + de la planificación general de la actrividat ecomónica $\}[2]$

VERBAL\{Futuro\}[6] \{Infinitivo\}[6] \{Presente: indicativo[2]/activo: subjuntivo[1]/ pasivo[1]\}[4] $\{$ Se + futuro\} $|2|$

ORACIONAL $\{$ El Estado $+\mathrm{f}$. verbal: futuro/presente $+\mathrm{f}$. determinativa $+\mathrm{l}$. nominal $\}[2]\{$ El Gobierno $+f$. verbal: futuro $+f$. determinativa $+f$. nominal $\}[2]$

D.1.6.5. Industria (EA: 10; CE: 149)

NOMINAL\{EI Estado\}[3] \{La legislación de $+\mathrm{f}$. nominal\}[3] \{Razones de $+\mathrm{f}$. nominal $\}[3]$ $\{$ Competencia $\}[2]$ \{Industria $\}[2]$ \{Las normas $\}[2]$ \{Bases $y+\boldsymbol{f}$. nominal + de la actividad económica $\}[2]\{$ Competenciat exclusiva + f. preposicional + las siguientes materias $\}[2]$ [F. nominal + general $\}[2]\{$ F. nominal + del Estado $\}[2]$

VERBAL\{Presente: indicativo[2]/subjuntivo[2]\}[4]

ORACIONAL\{F, verbal + competencia exclusiva + f. preposicional: en/sobre + las siguientes materias: Bases $y+r$. nominal + de la actividad económica $\}[2]$

D.1.6.6. Producción, distribución y transporte de energía (EA: 10; CE: 149)

ORACIONAL $\{$ F. verbal: presente + competencia exclusiva + f. preposicional: en/sobre + las siguientes materias liransporte de energía cuando salga de su $+\mathrm{f}$. nominal $+y$ su aprovechamiento afecte a otra Comunidal $\}[2]$

D.1.6.7. Comcrcio interior y libre circulación de bienes (EA: 10; CE: 51, 139, 149, 157)

NOMINAL\{Circulación $\}[5]$ \{Legislación $+\mathrm{f}$. adjetival $\}[5]$ [Legislación $\}[4]$ \{La libre circulación de + f. nominal\}[4! \{Bienes\}[3] \{Competencia\}][3] \{Territorio\}[3] \{La Comunidad Autónomat\}[3] $\{E$ t Estado $][2]$

$\{$ Medidas\}[2] \{Comercio interior\}[2] \{Legislación mercantil\}[2] \{La libre circulación de bienes\}[2] $\{$ Competencia exclusiva $+\mathrm{f}$. preposicional + las siguientes materias $\}[2]$ [Establecimiento de $+\mathrm{f}$. determinativa $+i$. nominal $\}[2]\{\mathrm{F}$. nominal + de mercancias $\}[2]\{\mathrm{F}$. nominal + de olros centros de contratación de mercancias] [2]

VERBAL\{Presente: indicativo[2]/subjuntivo[3]\}[5] \{Futuro\}[3] \{Podrá ctdoptar\}[2] 
ORACIONAL $\{\mathrm{F}$. verbal + competencia exclusiva $+\mathrm{f}$. preposicional: en/sobre + las siguientes materias: legislación mercantil $\}[2][\mathrm{F}$. determinativa $+\mathrm{f}$. nominal + podrá adoptar medidas que $+\mathrm{f}$. verbal: presente: subjuntivo + la libre circulación de $+\mathrm{f}$, nominal $]$ [2]

D.1.6.8. Ferias y mercados interiores (EA: 10; CE: 148)

ORACIONAL\{F. verbal: presente/futuro + competencia en las siguientes materias: Ferias interiores $\}$ |2!

D.1 6.9. Cooperativas y entidades asimilables, mutuas (EA: 10; CE: 129)

NOMINAL [Las formas de participación en la $+\mathrm{f}$. nominal\}[3] \{Cooperativas\} [2]

$\{$ Seguridad Social $\}[2]\{F$. nominal + asimilables $\}[2]\{F$. determinativa + legislación $+f$. adjetival $\}[2]$

VERBAL\{Futuro\}[3] \{Presente: indicativo[1]/subjuntivo[1]\}[2]

ORACIONAL $\{\mathrm{F}$. determinativa + f. nominal + f. verbal: futuro + las formas de participación en la $+\mathrm{f}$. nominal\}[2] \{Los poderes públicos $+\mathrm{f}$. verbal: futuro $+\mathrm{f}$. determinativa $+\mathrm{f}$. nominal $\}[2]$

D. 1.6.I0. Instituciones de crédito y cajas de ahorro (EA: 10; CE: 149)

NOMINAL\{F. nominal + de la ordenación de $+\mathrm{f}$. nominal $\}[2]$

VERBAL\{Presente $\}[3]$

ORACIONAL $\{\mathrm{F}$. verbal + competencia exclusiva + f. preposicional: en/sobre + las siguientes materias: $+\mathrm{f}$. nominal + de crédito, la ordenación de $+\mathrm{f}$. determinativa $+\mathrm{f}$. nominal $\}[2]$

D.1.7. Territorio, urbanismo, obras públicas, policía local, etc. (EA: 10; CE: 148)

D.1.7.1. Ordenación del territorio y del litoral

ORACIONAL $\{\mathrm{F}$. verbal: presente/futuro + competencia en las siguientes materias: Ordenación del territorio, urtanismo y vivienda $[2]$

D. 1.7.2. Urbanismo y vivienda (EA: 10; CE: 148)

ORACIONAL $\{\mathrm{F}$. verbal: presente/futuro + competencia en las siguientes materias: urbanismo y vivienda\}[2]

D.1.7.3. Obras públicas (EA: 10; CE: 148, 149)

ORACIONAL $\{\mathrm{F}$. verbal: presente/futuro + competencia en las siguientes materias: obras públicas de interés $+f$. preposicional: delen + su propio territorio $\}[2]\{\mathrm{F}$. verbal + competencia exclusiva $+\mathrm{f}$. preposicional: en/solbre + las siguientes materias: obras públicas de interés general afecte a $+\mathrm{f}$. determinativa + Conumidad Autónonta $\}[2]\{\mathrm{F}$. verbal + competencia + f. preposicional: en[2]/sobre[1] + las siguientes materias: obras públicas de interés\}[3]

D. I.7.4. Vigilancia y prolección de los edificios (EA: 10, 19; CE: 148)

NOMINAL $\{$ Vigilancia y protección de sus edificios e instalaciones $\}$ [3]

ORACIONAL[F. verbal; presente/futuro + competencia en las siguientes materias: Vigilancia y proteccion de sus edificios e instalaciones] [2]

D. 1.7.4.1. Adscripción de una Unidad del Cuerpo Nacional de Policía (EA: 19; CE: 149)

NOMINAL\{Competencia $\}[2] \quad\{$ El Estado $\}[2] \quad\{$ Estatuto $\}[2] \quad\{$ Policia $\}[2] \quad\{$ La Comunidad Autómom $\}[2\}$ [El articulo $+f$. adjetival + de $+f$. nominal $\}[2]\{$ Competencia de $+f$. nominal + de sus edificios e instalaciones\}[2] \{El ejercicio de la $+\mathrm{f}$. nominal $\}[2]\{\mathrm{F}$. determinativa + Ley Orgánica\}[2] $\{\mathrm{F}$. nominal + prevista $\}[2]$

VERBAL $\{$ Presente: indicativo[1]/subjuntivo[2]\}[3]

ORACIONAL L La Comunidad Autónoma podrá convenir $+[\ldots]+$ para el ejercicio de la $+\mathrm{f}$. nominal + prevista en el + [. nominal $\}$ [2]

D.1.7.5. Coordinación con las policías locales (EA: 10; CE: 148)

ORACIONAL $\{\mathrm{F}$. verbal: presente/futuro + competencia en las siguientes materias: La coordinación y denár facultades en relación con las policías locales\}[2]

D.1.8. Otros: estaddística y servicio meteorológico

D.1.8.1. Estadística para fines no cstatales (EA: 10; CE: 149)

ORACIONAL\{F. verbal: presente + competencia exclusiva $+f$. preposicional: en/sobre + las siguientes materias: Esaculistica para fines estatales $][2]$

D.1.8.2. Servicio neteorológico (EA: 10; CE: 149) 
ORACIONAL $\{\mathrm{F}$. verbal: presente + competencia exclusiva $+\mathrm{f}$. preposicional: en/sobre + las siguientes materias: Servicio meteorológico\}[2]

D.19. Disposición linal

D. 19.1. Polestad legislativa, reglamentaria y función ejecutiva de la Región (EA: 10; CE: 150)

NOMINAL $\{$ Ley $\}[4]\{$ Competencia $\}[3]\{$ Las Comunidades Autónontas $\}[3]\{$ Ley $+\mathbf{f}$ adjetival $\}[3]\{$ Los + f. nominal + fijados\}[3] \{F. nominal + estatal $\}[3]\{$ Control $\}[2]\{$ El Estado\}[2] \{Facultad $\}[2]$ $\{$ Marco $\}[2]$ Las Cortes Generales $\}[2]\{$ Normas legislativas $\}[2]\{$ Materia de $+f$. nominal + estatal $\}[2]$ $\{$ La potestad $+\mathrm{f}$. adjetival\}[2] \{ Susceptibles de $+\mathrm{f}$. nominal\}[2] $\{\mathrm{F}$. nominal + correspondiente $\}[2]\{\mathrm{F}$. nominal + legislativa $][3]$

VERBAL\{Futuro $\}[7] \quad\{$ Infinitivo\}[4] $\{$ Podrá + infinitivo $\}[3] \quad\{$ Se + presente[1]/ futuro[1]\}[2] $\{$ Presentc: indicativo[1]/ subjuntivo[1]\}[2]

ORACIONAL $\{\mathrm{F}$. determinativa $+\mathrm{f}$. nominal + podrá $+\mathrm{f}$. verbal: infinitivo + f. preposicional: alde + las Conumidades Autónomas facultad $\}[2]$

D.2. Materias de desarrollo legislativo y ejecución regional (EA: 1/; CE: 150)

NOMINAL\{F. nominal + fijados\}[3] \{Competencia $\}[2]$ \{Las Cortes\}[2] \{Materias $\}[2] \quad\{L a$ Comunidad Autonomat $\}[2]\{\mathrm{F}$. nominal + estatal $\}[2]\{\mathrm{F}$. nominal + legislativo $\}[2]$ [F. determinativa + $\{e y+f$ adjetival $\}[2]$

VERBAL\{Presente: indicativo[1]/subjuntivo[1]\}[2] \{Infinitivo\}[2] \{Futuro\}[2]

D.2.1. Sanidad, higiene, ordenación farmacéutica, etc. (EA: $1 / ; \mathrm{CE}: 12,148,149)$

NOMINAL $\{$ Coordinación $\}[2]$

ORACIONAL\{F. verbal: presente/futuro + $\mathrm{f}$. nominal + en las siguientes materias: Sanidad, higiene $\}[2]\{\mathrm{F}$. determinativa $+\mathrm{f}$. nominal $+\mathrm{f}$. verbal: presente/futuro + competencia $+\mathrm{f}$. preposicional: enlsobre + las signientes materias: sanidad $\}[2]$ [F. verbal $+\mathrm{f}$. nominal $+\mathrm{f}$. preposicional: sobrelen + las siguientes materias: $+\mathrm{f}$. nominal + farmacéutico\}[2] \{Corresponde a la $+\mathrm{f}$. nominal $+\mathrm{f}$. determinativa $+\mathrm{f}$. nominal + en las siguientes materias: productos farmacéuticos $\}[2]$

D.2.2. Montes, aprovechamientos forestales, etc. (EA: $1 /$; CE: 148, 149)

ORACIONAL $\{\mathrm{F}$. determinativa $+\mathrm{f}$. verbal: presente/futuro + competencias en las siguientes materias: montes, aprovechamientos forestales $\}[2]$ [F. verbal: presente + las siguientes materias: montes, aprovechamientos forestales, vias pecuarias $\}[2]$

D.2.3. Protección del medio ambiente (EA: 11 ; CE: 45, 148, 149)

ORACIONAL $\{\mathrm{F}$. verbal: presente + las siguientes materias: protección del medio ambiente. Normas adicionales de proteccion $\}[2]\{\mathrm{F}$. determinativa $+\mathrm{f}$. nominal $+\mathrm{f}$. verbal: presente/futuro + competencias en las siguientes materias: $+\mathrm{f}$. nominal $+\mathrm{f}$. preposicional + protección del medio ambiente $\}$ [2]

D.2.4. Régimen minero y energético (EA: 11; CE: 149)

ORACIONAL\{F. verbal: presente + f. preposicional: en/sobre + las siguientes materias: Régimen minero y energético $\}[2]$

D.2.5. Medios de comunicación social (EA: 11; CE: 20, 149)

NOMINAL\{El Estado\}[4] \{Medios de comunicación social\}[3] \{La Comunidad Autónoma\}[2] $\{$ Nomuls básicas del régimen de $+\mathrm{f}$. nominal\}[3] \{F. nominal + básica\}[3] \{Desarrollo\}[2] \{Ejecución\}[2] \{Prensa\}[2] \{Radio\}[2] \{Televisión\}[2] \{Normas básicas\}[2] \{Las siguientes materias\}[2] $\{$ En el marco de la + f. nominal + básica $\}[2]\{L o s$ grupos + f. adjetival + significalivos\}[2] \{F. nominal + de los medios de comunicación social dependientes del Estado\}[2]

VERBAL\{Presente: indicativo[2]/subjuntivo[3]\}[6] \{Futuro\}[2] \{Correspondan\}[2] \{Establezca\}[2]

ORACIONAL\{F. verbal: presente + f. preposicional: en/sobre + las siguientes materias: prensa, radio, televisión $y+\mathrm{f}$. determinativa + medios de comunicación social $\}[2]\{$ La ley $+\mathrm{f}$. verbal: futuro $+\mathrm{f}$. determinativa + i. nominal\} [2] \{ En el marco de la + f. nominal + básica + que establezca\} [2]

D.2.6. Sector pesquero (EA: 1/; CE: 149)

ORACIONAL $\{\mathrm{F}$. verbal: presente $+\mathrm{f}$. preposicional: en/sobre + las siguientes materias: $+\mathrm{f}$. nominal/f. verbal: infinitivo + el sector $\}[2]$

D.2.7. Defensa del consumidor y usuario (EA: 11 ; CE: 51, 149) 
NOMINAL\{F. nominal + económico\}[4] $\{$ Bases $\}[3]\{\mathrm{F}$. nominal + general $\}[3]$ \{Artículo\}[2] \{Coordinación $\}[2] \quad\{L a$ ejecución $\}[2] \quad\{E l$ Estado $\}[2] \quad\{L a$ ordenación $\}[2] \quad\{L a$ Comunidad Autónona\}[2] \{Legislación básica\}[2] \{Defensa del consumidor y usuario\}[2] \{Las siguientes materias\} $[2]\{$ Bases $y+f$. nominal + de la actividad económica $\}[2]\{\mathrm{F}$. nominal $+\mathrm{f}$. adjetival + de la Seguridad Social\}[2]

VERBAL\{Presente: indicativo[2]/subjuntivo[1]\}[3]

ORACIONAL $\{\mathrm{F}$. verbal: presente/futuro + defensa del consumidor y usuario $\}$ [2] $\{\mathrm{F}$. verbal: presente + f. preposicional: en/sobre + las siguientes materias: bases $\mathrm{y}+\mathrm{f}$. nominal + de la actividad económica][2]

D.2.8. Sistema de consultas populares (EA: 11; CE: 92, 149)

NOMINAL $\{$ El Estado\}[3] \{Ley\}[3] \{Autorización\}[2] \{Constitución\}[2] \{Convocatoria\}[2] \{Las siguientes materias $\}[2]\{\mathrm{F}$. nominal + de consultas populares $\}[2]\{\mathrm{F}$. nominal + del Estado $\}[2]\{\mathrm{F}$. nominal + de referéndum $\}[2]$

VERBAL\{Presente: indicativo[2]/subjuntivo[2]\}[4] \{Corresponder: presente: corresponde[1]/gerundio: correspondiendo[!] [? [2]

ORACIONAL $[\mathrm{F}$. verbal: presente $+f$. preposicional: en/sobre + las siguientes materias: $+\mathrm{f}$. nominal + de comsultas populares\}[2]

D.2.9. Colegios profesionales, ejercicio de profesiones tituladas, etc. (EA: 11; CE: 36)

ORACIONAL $\{\mathrm{F}$. verbal: presente/futuro + Colegios profesionales y el ejercicio de las profesiones titulades $\}[2]$

D.2.10. Competencias de desarrollo legislativo y ejecución de la enseñanza (EA: 16; CE: 149)

NOMINAL $\{$ El Estado $\}[5] \quad\{L a$ Comunidad Autónoma $\}[4] \quad\{E l$ artículo + f. adjetival $\}[4]$ \{Competencia\} [3] \{Regulación de las condiciones de $+\mathrm{f}$. nominal + de titulos $+\mathrm{f}$. adjetival\}[3] \{Cumplimiento\}[2] \{Desarrollo\}[2] \{Materia\}[2] \{Servicio\}[2] \{La Adninistración del Estado\}[2] $\{$ El articulo 27 de la Constitucion\}[2] \{El apartado I del articulo $+\mathrm{f}$. adjetival\}[2] \{Aspectos $+\mathrm{f}$. adjetival\}[2] \{ Una prestación $+f$. adjetival + del servicio público de la educación\} [2] \{Titulos $+f$. adjetival $\}[2]\{\mathrm{F}$. nominal + esencial $\}[2]\{\mathrm{F}$. nominal + público $\}[2]\{\mathrm{F}$. nominal + del sistema educativo $\}[2]$

VERBAL\{Presente: indicativo[4]/subjuntivo[3]\}[7] \{Futuro\}[5] \{Infinitivo\}[5] \{Poder: futuro: podrín[1]/presente subjuntivo: puedan[1] + infinitivo\}[2] \{Facilitará\}[2] \{Garantizar\} [2]

ORACIONAL\{la Commidad Autonoma + f. verbal: futuro + f. preposicional: alcon + lat administración del Estado $\}[2]\{$ El Estado $+\mathrm{f}$. verbal: futuro $+\mathrm{f}$, determinativa $+\mathrm{f}$. nominal $\}[2]\{\mathrm{F}$. determinativa $+f$, nominal + facilitara $+f$. determinativa $+f$. nominal $\}[2]$

D.3. Materias con función ejccutiva regional

D.3.1. Asociaciones (EA: 12; CE: 22)

NOMINAL\{Asociación: asociación[1]/asociaciones[4]\}[5]

VERBAL\{Presente: indicativo[4]/subjuntivo[4]\}[8] \{Futuro\}[3] \{Podrán ser + participio\}[2] $\{$ Participio\}[5\} $\{S e+$ presente $\}[2]$

ORACIONAL $\{$ Las asociaciones + f. verbal: presente[1]/futuro[2]\}[3]

D.3.2. Forias internacionales (EA: 12; CE: 148)

ORACIONAL\{F. verbal: presente/futuro + $\mathrm{f}$. nominal + en las siguientes materias: Ferias $+\mathrm{f}$. adjotival [2]

D.3.3. Gestión de prestaciones y servicios sociales del sistema de Seguridad Social (EA: I2; CE: 4I, 149)

NOMINAL $\{$ El Estado\}[3] \{Seguridad Social\}[3] \{Competencia $\}[2]\{$ Legislación\}[2] \{Servicios\}[2] $\{$ Sistena\} [2] \{Las siguientes materias\}[2] \{Régimen $+f$, adjetival\}[2] [La asistencia y prestaciones $+\mathrm{f}$. adjetival\}[2] \{Las normas + f. adjetival\}[2] \{Régimen + f. adjetival + de Seguridad Social $\}[2]\{F$. nominal + complementarias $\}[2]\{\mathrm{F}$. nominal + de las prestaciones $\}[2]\{\mathrm{F}$. nominal + público $\}[2]\{\mathrm{F}$. nominal + social $\}[2]\{$ F. nominal + suficientes $\}[2]$ 
VERBAL\{Presente: indicativo[2]/subjuntivo[3]\}[4] \{Establecer: presente subjuntivo: establezcath] I]/infinitivo: establecer[1]/participio: establecidas[1]\}[3] \{Futuro\}[3]

ORACIONAL\{F. verbal: presente + f. nominal + f. adjetival + f. preposicional: en/sobre + las siguientes materias: $+[\ldots]+\mathrm{f}$, nominal $+\mathrm{f}$. adjetival + de Seguridad Social $\}[2]$

D.3.4. Gestión de la asistencia sanitaria de la Seguridad Social (EA: 12; CE: 149)

ORACIONAL $\{\mathrm{F}$. verbal: presente $+\mathrm{f}$. nominal $+\mathrm{f}$. adjetival $+\mathrm{f}$. preposicional: en/sobre + las siguientes materias: F. nominal $+f$ adjetival + de la Seguridad Social $\}[2]$

D.3.5. Gestión de muscos, archivos y bibliotecas (EA: 10, 12; CE: 148, 149)

ORACIONALIF. verbal: presente/futuro + competencia en las siguientes materias: Museos, bibliotecas, conservatorios de missica de interés para la $+\mathrm{f}$. nominal] [2] [Corresponde a la $+\mathrm{f}$. nominal + las siguientes materias: museos, archivos, bibliotecas de interés de titularidad estatal que no $+\mathrm{f}$. verbal: presente: subjuntivo $[2]\{\mathrm{F}$. verbal: presente $+\mathrm{f}$. nominal $+\mathrm{f}$. preposicional: en/sobre + las siguientes materias: maseos, bibliotecas y archivos de titularidad estatal $\}[2]\{\mathrm{F}$. verbal + competencia excusivi $+\mathrm{C}$. preposicional: en/sobre + las siguientes materias: museos, archivos y bibliotecas de titularidad estatal $\}[2]\{\mathrm{F}$. verbal + competencia $+\mathrm{f}$. preposicional: en[2]/sobre[1] + las siguientes materias: museos, bibliotecas $\}[3]$

1).3.6. Pesals y medidas (EA: 12; CE: 149)

ORACIONAL $\{\mathrm{F}$. verbal: presente + $\mathrm{f}$. nominal + f. adjetival + f. preposicional: en/sobre + las siguitentes materias: Pesas y medidas \}[2]

D.3.7. Productos farmacéuticos (EA: 11, 12; CE: 148, 149)

NOMINAL\{Corrdinación $\}[2]$ [La Comunidad Autónoma $\}[2]$

ORACIONAL\{F. verbal: presente/futuro + f. nominal + en las siguientes materias: Sanidad, higiene $\}[2]\{\mathrm{F}$. determinativa $+\mathrm{f}$. nominal $+\mathrm{f}$. verbal: presente/futuro + competencia $+\mathrm{f}$. preposicional: en/sobre + las siguientes materias: sanidad\}[2] [F. verbal: presente $+f$. nominal + f. adjetival $+f$. preposicional: sobrelen + las siguientes materias: productos farmacéutico\}[2] [Corresponde a la $+\mathrm{f}$. nominal $+[$. determinativa $+[$. nominal + en las siguientes materias: productos farmacéuticos $\}[2]$

D.3.8. Propicdad intelcctual e industrial (EA: 12; CE: 149)

ORACIONAL $\{\mathrm{F}$. verbal: presente $+\mathrm{f}$. nominal $+\mathrm{f}$. adjetjval $+\mathrm{f}$. preposicional: en $/$ sobre + las signiemes materias: propiedad intelectual e industrial $\}[2]$

D.3.9. Legislación laboral (EA: 12; CE: 149)

ORACIONAL $\{\mathrm{F}$. verbal: presente $+\mathrm{f}$. nominal $+\mathrm{f}$. adjetival $+\mathrm{f}$. preposicional: en/sobre + las siguientes materias: Legislación laboral\} [2] [Corresponde $a+f$. determinativa $+f$. nominal $\}[2]$

D.3.10. Tratados internacionales (EA: 12; CE: 93, 149)

NOMINAL $\{\mathrm{F}$. nominal + internaciomal\}[6] \{Tratados\}[4] \{Competencia\}[3] [Gobierno\}[3] \{Materias\}]3] \{Corresponde\}[2] \{El Estado\}[2] \{La Region\}]2] \{Tratados internacionales\} [2] [F. determinativa + organización internacional\}[2]

VERBAL $\{$ Presente: $\quad$ indicativo[1]/subjuntivo[3]\}[4] \{Participio\}[3] $\{$ Se + presente subjuntivo[! [ / /uturo].1]\}[2] \{Futuro\}[2]

ORACIONAL $\{$ Corresponde $a l a+f$, nominal $+l a+f$, nominal $\}[2]$

D.4. Ampliación de las competencias (EA: 13; CE: 148, 149)

NOMINAL $\{$ La Comunidad Autónoma\}[7] \{Competencia $\}[6] \quad\{$ El Estado\}[4] [Estatutos\}[3] [Materias\}[3] \{Acuerdo\}[2] \{El articulo $+\mathbf{f}$, adjetival\}[2] \{Constitución $\}[2]\{$ Derecho\}[2]

VERBAL\{Participio\}[10] \{Futuro\}[8] \{Atribuido\}[4] \{Podrá + infinitivo\}[4] \{Esté atribuido\}[3] \{Podri ampliar\}\{2] \{Transcumidos\}[2] \{Asumir: infinitivo: asumir[2] /pretérito perfecto subjuntivo: hay'an asumido][2] \{Corresponder: futuro: corresponderá[1]/infinitivo: corresponder[1]\}[2]

ORACIONAL[Transcurridos cinco años la Conunidad Autónoma podrá ampliar sus competencias\}]2] \{Materias no atribuidas al Estado\}[2] \{La Comunidad Autónoma podrâ $+\mathrm{f}$. verbal: infinitivo $+\mathrm{f}$. determinativa + competencias $\}[3]$

D.4.1. Procedimientos para asumir competencias (EA: 13; CE: 150) 
NOMINAL\{La Cominidad Autónoma $\}[5]$ \{Competencia $\}[4]$ \{Ley\}[4] \{El Estado\}[3] \{Ley + f. adjetival $\}[3]\{$ Los + f. nominal + fijados $\}[3]\{$ Caso $\}[2]\{$ Facultad $\}[2]$ Transferencia $\}[2]\{$ Las Cortes Genemales\}[2] \{Nomuls legislativas\}[2] \{Materia de $+\mathrm{f}$. nominal + estatal\}[2] $\{\mathrm{F}$. nominal + correspondiente $\}[2\}$

VERBAL $\{$ Futuro\}[7] \{Infinitivo\}[6] $\{$ Podrá + infinitivo $\}[5] \quad\{$ Podrá asumir\}[2] \{Presente subjuntivo\}[2] $\{\mathrm{Se}+$ presente subjuntivo[1]/futuro[1]\}[2] \{Reserve $\}[2]\{$ Participio $\}[2]$

ORACIONAL $\{$ La Commidad Autónoma podrá asumir competencias $\}[2]$ [F. determinativa $+f$. nominal + podra $+f$. verbal: infinitivo $+f$. preposicional: alen + las Comunidades Autónomas facullad $\}[2]$

D.5. Acuerdos de cooperación con otras Comunidades (EA: 19; CE: 145)

NOMINAL LLas Cortes\}[6] \{Convenio\}[5] \{Autorización\}[4] [Comunicación\}[4] \{Comunidades\}[4] \{Comunidades Autómonas\}[3] \{Cortes Generales\}[3] \{Gestión\}[3] [El mismo\}[2] \{Región\}[3] [Los supuestos\}[2] \{Requisitos\}[2] [La Región de Murcia\}[2] \{La autorización de las Cortes\}[2] \{Autorización de las Cortes Generales $\}[2]$ \{La gestión y prestación de servicios propios $\}[2]\{L a$ recepción de la comunicación $\}[2]$ \{Acuerdos de cooperación $\}[2]$ [El «Boletín Oficial de $+\mathrm{f}$. determinativa + f. nominal $\}[2]$ \{Previa $+\mathrm{f}$. nominal + alde + las Cortes $\}[2]$ [F. nominal + de gesiing $\}[2]$

VERBAL\{Futuro\}[8! \{Infinitivo\}[7] \{Podrá + infinitivo\}[6] \{Participio\}[4] \{Presente: indicativo[ [1]/subjuntivo[2]\}[3] \{Podrá celebrar\}[2]

ORACIONAL\{F. verbal/f. determinativa + acuerdos de cooperación $+\mathrm{f}$, preposicional: con/entre $+\mathrm{f}$. deteminativa + Comunidades Autónomas $+f$. verbal: presente/f. adjetival + autorización de las Cortes Generales $\}[2]\{\mathrm{F}$. determinativa $+\mathrm{f}$. nominal + podrá celebrar convenios $+\mathrm{f}$. preposicional; con/entre + f. determinativa +1 . nominal/f. pronombre +para la gestión y prestación de servicios propios ] [2]

D.6. Disposiciones finales

D.6.1. Acomodación a las leyes cstatales (EA: 15; CE: 150)

NOMINAL[Caso\}[2\} \{Leyes\}[2] \{La Comunidad Autonoma\}[2] \{Los principios $+\mathrm{f}$. adjetival\}[2] [F. dererminativa + disposiciones normativas\} [2]

VERBAL\{Presente: indicativo[2]/subjuntivo[2]\}[4] \{Futuro\}[2] \{Infinitivo\}[2] \{Participio\}[2]

E. TÍTULO II: DE LOS ÓRGANOS INTITUCIONALES

E. 1. CAPÍTULO I: DE LOS ÓRGANOS DE LA COMUNIDAD AUTÓNOMA

E. 1.1. Denominación de los órganos institucionales (EA: 20; CE: 147)

NOMINAL $\{L a+f$ nominal + de las instituciones Autónomas propias $\}[3]$

E.1.2. Representación del pueblo (EA: 2I; CE: 66)

ORACIONAL $\{L a+f$. nominal + representa al pueblo + f. adjetival $\}[2]$

E. 1.3. Inviolabilidad de la Asamblea Regional (EA: 21; CE: 66)

ORACIONAL $\{$ Ia + f. nominal + es inviolable $\}[2]$

E.2. CAPÍTULO II: DE LA ASAMBLEA REGIONAL.

E.2.1. Ejercicio de la potestad logislativa y competencias (EA: 22; CE: 66)

ORACIONAL $\{l a l+f$ nominal + f. verbal: presente + la potestad legislativa $+[\ldots]+f$, verbal: aprobar: infinitivo/presentc $+f$. determinativa + Presupuestos $+f$. verbal: controlar: infinitivo/presente $+I a$ acción del Gribiemo y las competencits que le $+\mathrm{f}$. verbal: presente + la Constitución ] [2]

E.2.2. Otras competencias de la Asamblea Regional

E2.2.1. Designación de senadores y representación proporcional (EA: 23; CE: 69)

ORACIONAL $\{\mathrm{F}$. verbal: presentelfuturo + a la Asamblea + f. adjetival + f. verbal: designar: infinitivo/futuro $+\mathrm{f}$. determinativa + senador $+\mathrm{f}$. preposicional: locución + lo que establezca $+\mathrm{f}$. determinativa $+f$. nominal, + que asegurará, en todo caso la adecuada representación proporcional $\}[2]$ E.2.2.2. Formulación de proyectos de Icy (EA: 23; CE: 87)

ORACIONAL\{F. verbal: presente/futuro + solicitar del Cobiemo la $+\mathrm{f}$, nominal + de proyecto de ley + 1. relacional $+\mathrm{f}$. verbal $+\mathrm{f}$. preposicional: alante + el Congreso proposición de ley\} [2]

E.2.2.3. Previsioncs polílicas, cconómicas y sociales (EA: 23; CE: 13/) 
NOMINAL\{F. nominal + econónica $\}[3]$ [El Gobierno $\}[2]$ [Las previsiones $\}[2]$ \{La Comunidad Autónoma $\}[2]$ \{Los proyectos de planificación\} $[2]$ \{Otras organizaciones $+f$ adjetival\} $\{3\}$ [Las previsiones de indole $+f$. adjetival $\}[3]$

VERBAL\{Futuro $\}[3] \quad\{$ Infinitivo\}[2] \{Presente: indicativo[1]/pasivo: subjuntivo[1]\} [2] \{Se + futuro\}[2]

E.2.2.4. Modilicación y creación de entidades territoriales (EA: 23; CE: 141, 148, 152)

NOMINAL\{Competencia\}[2] [Estatuto\}[2] [Municipio\}[2] [Alteración de los términos\}[2] $\{$ Altercición de los $+\mathrm{f}$. nominal $\}[2]\{\mathrm{F}$. nominal + local $\}[2]\{\mathrm{F}$. nominal + territoriales $\}[2]$

VERBAL\{Futuro\}[4] \{Infinitivo\}[4] \{Participio\}[3] \{Presente: indicativo[1]/ subjuntivo[2]\}[3] \{Podrấ + infinitivo] [2]

E.2.2.5. Establecimiento de tributos (EA: 23; CE: 133)

ORACIONAL[F. verbal: presente/futuro + establecer y exigir tributos + f. preposicional + la Constitucion $\}[2]$

E.2.2.6. Responsabilidad política (EA: 23; CE: /13)

ORACIONAL\{F. verbal: presente + exigir responsabilidad politica\} [2]

E.2.2.7. Aprobación de la Cuenta General de la Comunidad Autónoma (EA: 23; CE: 136)

NOMINAL $\{$ La Cuenta General de $+\mathrm{f}$. determinativa $+\mathrm{f}$. nominal $\}[2]\{E l+\mathrm{f}$. nominal + de la Cuenta General del Estado][2]

VERBAL\{Futuro\}[2] \{ Infinitivo\}[2]

E.2.2.8. Interposición del recurso de inconstitucionalidad (EA: 23; CE: 16I)

ORACIONAL $\{\mathrm{F}$. verbal: infinitivo + el recurso de inconstitucionalidad contra leyes, disposiciones $+\mathrm{f}$. adjetival/f: nominal + con fuerza de ley\}[2] \{El Tribunal Constitucional es competente para conocer de $+f$. detcrminativa $+f$. nominal $\}[2]$

E.2.3. Elección de los iniembros del Poder Legislativo (EA: 24; Disp.Tran. CE: 68)

ORACIONAL\{F. determinativa $+f$. nominal $+f$. verbal: presenteffuturo $+f$. preposicional: de/con + diputados elegidos $+f$. preposicional: por/mediante + sufragio universal, libre, igual, directo y secreto][2] [Diputados elegidos por sufragio universal, igual, directo y secreto] [3]

E.2.3.1. Representación proporcional (EA: 24, Disp.Tran. CE: 152)

NOMINAL $\{$ Representacion $\}[3] \quad\{$ Sistema $\}[3]$ \{Funciones $+f$. adjetival $\}[2] \quad\{\mathrm{F}$. nominal + de representación proporcional $\}[2]$

VERBAL\{Se + presente[1]/[uturo[2]\}[3] \{Presente: indicativo[1]/subjuntivo[1]\}[2] \{Futuro\}[3] \{Participio\}[2]

E.2.4. Número de diputados e incompatibilidades (EA: 24; CE: 68,70$)$

NOMINAL\{Circunscripción\}[2] \{Diputados\}[2] $\{$ Ley\}[2] $\{$ Las causas de inelegibilidad $e$ incompanibilided $\mid 2]$

$\{$ El numero $+\{$. adjetival $+a+f$. adjetiva $+y$ cinco $\}[2]\{$ Un $+f$. nominal + de 400 Diputados $\}[2]\{\mathrm{F}$. nominal + electoral $\}[2]\{\mathrm{F}$. nominal + regional $\}[2]$

VERBAL\{Futuro\}]3\}]

ORACIONAL $\{\mathrm{F}$. determinativa $+f$. nominal $+\mathrm{f}$. verbal: futuro + las causas de inelegibilidad $e$ incompratibilidad] [2]

E.2.5. Diputados regionales

E.2.5.1. Mandato (EA: 25; CE: 67)

ORACIONAL $\{$ Los + f. nominal + f. adjetival + no + f. verbal: cstar: presente/futuro + f. adjetival: participio + f. preposicional: a/por + mandato imperativo $][2]$

E.2.5.2. Inviolabilidad en el ejercicio de sus funciones (EA: 25; CE: 7I)

ORACIONAL\{Los diputados gozarán de inviolabilidad por las opiniones + f. verbal: (que) presente subjunlivo/participio + en el ejercicio de sus funciones\}[2]

E.2.5.3. Detención (EA: 25, 33; CE: 71, 102)

ORACIONAL $\{\mathrm{F}$. determinativa $+f$. nominal + Gobierno no podrán ser detenidos ni retenidos por los presuntos atos delictivos cometidos en el territorio de la Región, sino en caso de flagrante delito, en 
tanto decide ol Tribunal Superior de Justicia sobre su inculpación, prisión, procesamiento y juicio. Fuera de la Región la responsabilidad penal será exigible en los mismos términos ante la Sala de lo Penal del Tribunal Supreno\} $[2]$ \{Los diputados durante su mandato $+\mathrm{f}$. adverbial: nolsólo + podrán ser detenidos en caso de flagrante delito $\}[3]$ \{La responsabilidad $+\mathrm{f}$. adjetival + será exigible ante la Sala de lo Penal del Tribunal Constitucional\} [2]

E.2.6. Sesiones de la Asamblea Regional

E.2.6.1. Sesiones públicas (EA: 26; CE: 80)

ORACIONAL Las sesiones plenarias de $l a+\mathrm{f}$. nominal $+\mathrm{f}$. verbal: ser: presente/futuro + públicas, salvo $+[\ldots]+[$. preposicional: alen + el Reglamento $\}[2]$

E.2.6.2. Adopción de acuerdos (EA: 26; CE: 79)

ORACIONAL $\{$ Para $+\mathrm{f}$. nominal/f. verbal: infinitivo + acuerdos, $l a+f$. nominal $+\mathrm{f}$. verbal: presente + estar reunida reglamentariamente y con asistencia de la mayoria de sus miembros. + $\mathrm{F}$. verbal: participio/f. determinativa + acuerdos $+\mathrm{f}$. verbal: futuro + por mayoria $+[\ldots]+$ las leyes o el Reglamento $+\mathrm{f}$. verbal: presente subjuntivo][2]

E.2.6.3. Condición del voto (EA: 26; CE: 79)

ORACIONAL $\{$ El voto es personal e indelegable $\}[2]$

E.2.7. Autonomía de la Asamblea

E.2.7.1. Reglamento, presupuesto y Estatuto (EA: 27; CE: 72)

ORACIONAL $\{L a+f$. nominal + establece su propio Reglamento, aprueba su presupuesio y regula el Estatuto de $+\mathrm{f}$, determinativa $+\mathrm{f}$. nominal. $+\mathrm{F}$. determinativa $+\mathrm{f}$, nominal $+\mathrm{f}$. verbal: presente/futuro + f. nominal + final $+[\ldots]+$ mayoría $\}[2]$

E,2.7.2. Mesa de la Asamblea Regional (EA: 27; CE: 72)

ORACIONAL $[L a+f$. nominal + f. verbal: elegir: presente/futuro + su Presidente y los demás $+\mathrm{f}$. nominal + de $+\mathrm{f}$. determinativa + Mesa $\}[2]$

E.2.7.3. Disolución de la Asamblea Regional (EA: 27; CE: /15)

NOMINAL\{La disolución\}[4] \{La disolución de $+\mathrm{f}$. determinativa $+\mathrm{f}$. nominal\}[4] \{Decreto\}[2] \{Elecciones\}[2] \{Gobiemo\}[2] $\{E l$ Presidente $\}[2] \quad\{S u$ exclusiva responsabilidad $\}[2] \quad\{$ Previa deliberación del Consejo de $+\mathrm{f}$. nominal $\}[2]$

VERBAL $\{$ Futuro\}[6] $\{$ Podrá + infinitivo $\}[2]\{S e+$ futuro $\}[2]$

ORACIONAL $\{$ El Presidente, previa deliberación del Consejo de $+\mathrm{f}$. nominal + y bajo su exclusiva responsabilidad, podrá $+\mathrm{f}$. verbal: infinitivo + la disolución de $+\mathrm{f}$. determinativa $+\mathrm{f}$. nominal $\}$ [2]

E.2.7.3.1. Limitaciones para la disolución de la Asamblea (EA: 27; CE: 115)

ORACIONAL $[\mathrm{F}$. determinativa $+\mathrm{f}$. nominal + no podrá $+\mathrm{f}$. verbal: infinitivo + la disolución cuando + f. verbal: presente $+e n+f$. nominal + tma moción de censura $\}[2]\{F$. verbal: futuro $+f$. determinativa/f. adjetival + disolución antes de que transcurra un año desde la $+\mathrm{f}$. adjetival $+\mathrm{f}$. nominal $\}[2]$

E.2.8. Funcionamiento de la Asamblea Regional

E.2.8. 1. Pleno y comisiones (EA: 28; CE: 75)

ORACIONAL $\{L a+f$. nominal $+f$. verbal: funcionar: presente/futuro + en pleno $y+f$. preposicional: en/por + comisiones $\}[2]$

E.2.8.2. Clases de comisiones (EA: 28; CE: 75)

NOMINAL $\{$ Comisiones permanentes $\}[2]$

E.2.8.3. Diputación permanente (EA: $28 ; \mathrm{CE}: 78$ )

NOMINAL $\{$ La Cámara $\}[3]$ \{Funciones $\}[2]\{S u$ mandato $\}[2]\{$ El artículo + f. adjetival $\}[2][\mathrm{F}$. determinativa + Diputación Permanente\} [2]

VERBAL\{Participio\}[7] \{Futuro: indicativo[3]/subjuntivo: perfecto activo[1]/ pasivo[1]\}[5] [Presente: indicativo[2]/ subjuntivo[1]\}[3] \{Estar + participio; presente: estén[2]/futuro: estará[1]\}[3] \{Asumir: futuro: asumiráf [1]/infinitivo: asumir[1]\}[2] \{Esté reunida\}[2] \{Expirar: subjuntivo: pretérito perfecto: haya expirado[1]/futuro perfecto: hubiere expirado[1]\}[2] 
ORACIONAL\{F. determinativa + Diputación Permanente $+[\ldots]+[$. verbal: asumin: futuro/infinitivo + las + l. noninal $+[\ldots]+f$. verbal: expirar: subjuntivo: pretérito perfecto/futuro perfecto + su mandato] $[2]$

E.2.9. Iniciativa legislativa

E.2.9.1. Iniciativa por parte de la Asamblea (EA: 23, 30; CE: 87)

NOMINAL $\{$ La Asamblea\}[4] \{F. nominal + de ley\}[4] \{Gobierno\}[3] \{Congreso\}][2] \{Miembros de lat Asamblea $\}[2]$ \{Proposición de ley\}[2] \{Proposición de ley\}[2] $\{$ El artículo $+\mathrm{f}$. adjetival $\}[2]\{L a+\mathrm{f}$. nominal + de proyecto de ley $][2]$

VERBAL $\{$ Presentc\} [2] \{Podrín + infinitivo\}[2] \{Infinitivo\}[4] \{Participio\}[3] \{Solicitar\}[2]

ORACIONAL $\{\mathrm{F}$. verbal: presente/futuro + solicitar del Gobierno la $+\mathrm{f}$. nominal + de proyectos de ley $+[$. relacional $+\mathrm{f}$. verbal: infinitivo $+\mathrm{f}$. preposicional + el Congreso proposición de ley\} $[2]\{\mathrm{F}$. verbal: presente + a la Ascmblea\}[2]

E.2.9.2. Iniciativa popular (EA: 30; CE: 87)

NOMINAL $\{$ La inicialiva $\}[3]\{$ Ley\}[3] \{La iniciativa popular $\}[2]\{$ La iniciativa de los $+\mathrm{f}$. nomina] $\}[2]$ VERBAL\{ $($ Se $)$ regulará $\}[2]$

ORACIONAL\{ $\mathrm{F}$. determinativa $+\mathrm{f}$. nominal/Se + regulará la iniciativa popular $\}[2]$

E.2.10. Promulgación y publicación de las leyes (EA: 30; CE: 9I)

NOMINAL $\{$ Publicación $\}[4]$ \{Las leyes $+\mathrm{f}$. adjetival\}[3] \{F. determinativa + publicación en el "Boletín oficial de $+\mathrm{C}$. determinativa $+\mathrm{f}$. nominal»\}[3] \{El Rey\}[2] \{Plazo de quince días\}[2] \{Las leyes aprobadas $\}[2] \quad\left\{S_{u}\right.$ inmediata publicación $\}[2]$ \{Su publicación en el "Boletín oficial de $+\mathrm{f}$. determinativa $+[$. nominal» $\}[2]\{\mathrm{F}$. nominal + generales $\}[2]\{\mathrm{F}$. determinativa + publicación en el "Boletin Oficial de la Región de Murcia»\}[2]

VERBAL\{Futuro\}[7] \{Disponer: futuro: dispondrá[1]/presente subjuntivo: dispongan[1]\}[2] \{Promulgar: futuro: activo: pronulgará[1]/pasivo: serán promulgadas [1]\}[2]

ORACIONAL [Pasiva/activa: Las leyes aprobadas por la $+\mathrm{f}$. nominal + serán promulgadas en el plazo de quince dias por el $+\mathrm{f}$. nominal $+\mathrm{f}$. relacional: y/que $+\mathrm{f}$. verbal: futuro + su inmediata publicación!!2]

E.3. CAPÍTULO III: DEL PRESIDENTE DE LA COMUNIDAD AUTÓNOMA.

E.3.1. Elección del Presidente (EA: 31; CE: 99, 152)

NOMINAL $\{$ El Presidente $\}[6]\{F$. determinativa + confianza $\}[6]\{$ Mayoria $\}[5]\{$ [El Rey $\}[5]\{L a$ Ascimblea $\}[4]\{$ Sus miembros $\}[4]\{$ El Presidente $d e+f$. determinativa $+[$. nominal $\}[4]\{\mathrm{F}$. deteminativa $+f$. nominal + del Congreso $[4]$ \{Investidura\}[3] [Eleccion $\}[3]$ \{El Congreso de los Diputades\} $\}$ 3] $\{$ EI + f. nominal + anterior\}[3] \{Cámara\}[2] \{Nuevas elecciones\}[2] \{El apartado amerior $\}[2]$ \{El Presidente del Congreso\}[2] \{Mayoria simple $\}[2]\{$ La confianza de $+\mathrm{f}$. determinativa + f. nominal $\}[2\}$ Mayoria absoluta de $+\mathrm{f}$. determinativa + miembros $\}[2]\{E l+\mathrm{f}$. nominal $+d e l a$ Ascmblea $\}[2]\{E l+f$. nominal + politico $\}[2]\{\mathrm{F}$. nominal + del Gobiemo $\}[2]\{\mathrm{F}$. determinativa + condidato $\}[2]$

VERBAL\{Participio\}[17] $\{$ Se + presente[1]/futuro[5]/pretérito perfecto subjuntivo [1]\}[7] \{Infinitivo\}[3] \{Nombrar: futuro: nombrará[1]/participio: nombrado[2]\}[3] \{Presente: indicativo[1]/subjuntivo[2]\}[3] \{Disolverâ\}[2] \{Elegido\}[2] \{Previsto\}[2] \{Se basarât\}[2] \{Transcurrido\}[2] \{Gerundio\}[2] \{Convocar: futuro: convocará[1]/gerundio: convocando[1]\} [2] \{Proponcr: futuro: propondrá[1]/participio: propuesto[1]\}[2] \{Obtener: Subjuntivo: futuro: ohtwviere[1]/futuro perfecto: hubiere obtenido[1]\}[2] [Otorgar: participio: otorgada[1]/futuro subjuntivo: otorgare[1]\}[2] \{Futuro: indicativo[4]/ subjuntivo: futuro[2]/futuro perfecto[2]

ORACIONAL\{F. determinativa + Presidente elegido por la Asamblea de entre sus miembros y nombrado por el Rey][2] [Si transcurrido el plazo de dos meses + preposicional + la primera votación de investidura ningtin candidato hubieralhubiese obtenido la confianza, el $+\mathrm{f}$. nominal + disolverá, $+\mathrm{f}$. pronombre/f. adjetival $+\mathrm{f}$. nominal, $+\mathrm{f}$. verbal: convocar: gerundio/futuro + nuevas elecciones $\}[2]\{$ La elección sera por mayoría $+\mathrm{f}$. adjetival $\}[2]$

E.3.2. Representación de la Región (EA: 31; CE: 152) 
ORACIONAL[A $+\mathrm{f}$. nominal/f. pronombre + corresponde la suprema representación de la $+\mathrm{f}$. nominal $+y$ la ordisaria del Estado en $+\mathrm{f}$, nominal/f. pronombre $\}[2]$

E.3.3. Responsabilidad política del Presidente (EA: 31; CE: 98, 152)

ORACIONAL[E] Presidente dirige y coordina la acción del (Consejo de) Gobierno $+f$. verbal: presente/futuro + políticamente ante la Asamblea $\}[2]^{9}$ [El Presidente + f. verbal: presente/futuro + polificamente ante la Asamblea\}[3]

E.3.4. Ccse del mandato presidencial (EA: 31; CE: 101 )

ORACIONAL $\{E]+\mathrm{f}$. nominal + cesa + f. preposicional: porlde + pérdida de la confianza, $+[\ldots]+$ previstos en $+\mathrm{f}$. determinativa $+\mathrm{f}$. nominal, por dimisión, fallecimiento $\}[2]$

E.4. CAPÍTULO IV: DEL CONSEJO DE GOBIERNO.

E.4.1. Competencias del Consejo de Gobierno

E.4.1.1. Función ejecutiva, gobierno y administración (EA: 32; CE: 97, 152)

NOMINAL $\{$ E Gobiemo\}[4] [La función $+\mathrm{f}$, adjetival\}[4] \{La administración $\}[3]\{$ La políica $+\mathrm{f}$. adjetival \}|3] \{ El Estatuto $\}[2]$ \{La potestad reglamentaria $\}$ [2] \{La administración $+\mathrm{f}$. adjetival $\}[2]\{\mathrm{F}$. determinativa + Consejo de Gobierno $\}[2]$ \{La función ejecutiva $\}[3]$

VERBAL $\{$ Presente\}[4] \{Participio\}[3] \{Dirige $\}[2]\{S e+$ presente[1]/futuro[1]\}[2]

ORACIONAL\{E\} Consejo de Gobierno dirige la política, + f. verbal: gerundio/presente + la función ejecutiva y la polestad reglamentaria\}[2]

E.4.1.2. Interposición del recurso de inconstitucionalidad (EA: 32; CE: 162)

ORACIONAL $\{E I+[$. nominal + de Gobierno está $+\mathrm{f}$. verbal: participio + para interponer el recurso de inconstinucionalidad $\}[2]$

E.4.1.3. Contlictos de competencia (EA: 32; CE: 161)

ORACIONAL $\{E l+f$. nominal $+f$. verbal: presente $+f$. adjetival/f. verbal: participio + para $+f$. verbal: infinitivo + los conflictos de competencia $+\mathrm{f}$. preposicional: conlentre + el Estado $+\mathrm{f}$. relacional: $y / o+$ f. determinativa + Comunidades Autónomas $\}[2]$

E.4.2. Composición del Consejo de Gobierno (EA: 32; CE: 98)

ORACIONAL $\{$ El (Consejo de) Gobiemo $+\mathrm{f}$. verbal: presente $+\mathrm{f}$. preposicional: por/de + el Presidente, el Vicepresidente, en su caso, los $+\mathrm{f}$. nominal, $+q u e+f$. determinativa $+\mathrm{f}$. nominal $+\mathrm{f}$. verbal: presente: indicativo/subjuntivo\}[2]

E.4.3. Principios en la actuación del Consejo de Gobierno (EA: 32; CE: 103)

ORACIONAL $\{\mathrm{F}$. determinativa $+f$. nominal $+f$. verbal: actuar: presente/futuro $+f$. preposicional + los principios $d e+\mathbf{f}$. nominal + jerarquia $\}[2]$

E.4.4. Aspectos no regulados por el Estatuto (EA: 32, 33; CE: 103)

ORACIONAL En lo no previsto en este Estatuto, una ley de la Asamblea, aprobada con el voto favorable de la mayoria de sus miembros, regulara $+\mathrm{f}$. determinativa $+\mathrm{f}$. nominal\}[2] [F. detcrminativa + ley regulará el Estafuto de $+\mathrm{f}$. determinativa $+\mathrm{f}$. nominal $\}[2]\{\mathrm{F}$. determinativa + ley regulara $+\mathrm{f}$. detcrminativa $+\mathrm{f}$. nominal $\}[3]$

E.4.5. Responsabilidad política (EA: 33; CE: 108)

ORACIONAL $\{$ El (Consejo de) Gobiemo responde + f. adverbial + ante + f. determinativa + f. nominal + โ. adverbial: solidariamentelde forma solidaria $][2]$

E.4.6. Cese del Consejo de Gobierno (EA: $33 ;$ EA: $3 I, 10 I$ )

ORACIONAL $\left\{E l+\int\right.$. nominal $+f$. verbal: cesar: presente[2]/futuro[1] $\}[3]\{E l+f$. nominal + cesa $+\mathrm{f}$. preposicional: portde + pérdida de la confianza, $+[\ldots]+$ previstos en $+\mathrm{f}$. determinativa $+\mathrm{f}$. nominal, por dimision, fallecimiento\} [2] [El (Consejo de) Gobiemo cesa\}[2]

E.4. 7. Cucstión de confianza y moción de censura

E.4.7.1. Cucstión de conlianza (EA: 33; CE: //2)

\footnotetext{
"Se incluye entre paréntesis (Consejo de) puesto que son dos órganos con las mismas funciones de representación y desde el punto de vista léxico no implica ningún cambio significativo.
} 
ORACIONAL $\{$ El Presidente del (Consejo de) Gobierno, previa deliberación de + f. nominal/f. pronombre + puede plantear ante $+\mathrm{f}$. determinativa $+\mathrm{f}$. nominal + la cuestión de confianza sobre su programa o sobre una declaración de política general. La confianza se entenderá otorgada cuando vote a favor de la misma la mayoría simple de los diputados\}[2]

E.4.7.2. Presentación de la dimisión (EA: 33; CE: 114)

NOMINAL\{El Gobiemo\}[4] \{La Asamblea $\}[3]$ \{Su dimisión $\}[3]\{$ El Rey\}[3] $\{$ El artículo + f. adjetival $\}[3] \quad\{\mathrm{F}$. determinativa + confianza $\}[3] \quad\{$ El Congreso $\}[2] \quad\{$ La Asamblea Regional $\}[2]$ \{Presidente del Gobiemo\}[2] \{Presidente de la $+f$. nominal $\}[2]$

VERBAL\{Futuro\}[5] \{Participio\}[5] \{Presentará\}[3] \{Presente: indicativo[2]/ subjuntivo[1]\}[3]

ORACIONAL $\{S i+f$. determinativa $+f$. nominal $+f$. verbal: presente/futuro + su confianza $+\mathrm{f}$. nominal/fi. pronombre + presentará su dimisión] [3]

E.4.7.3. Moción de censura por mayoría absoluta (EA: 33; CE: 1/3)

ORACIONAL $\{\mathrm{F}$. determinativa $+\mathrm{f}$. nominal + puede exigir la responsabilidad política del (Consejo de) Gobierno, mediante la adopción, por mayoría absoluta de $+f$. determinativa + moción de censuru\} $[2]$

E.4.7.4. Aprobación y propuesta de la moción de censura (EA: 33; CE: 1/3)

ORACIONAL $\{$ La moción de censura deberá ser +f. verbal: participio + por + f. nominal +f. adjetival, + al menos, de los diputados, habrí de incluir un candidato a la Presidencia del Gobierno\}[2]

E.4.7.5. Votación de la moción de censura (EA: 33; CE: 113)

ORACIONAL La moción de censura no podrá ser votada hasta que transcurran cinco días desde su presentación + f. verbal: poder: gerundio/futuro: pudiendo/podrán + presentarse en los dos primeros dias de dicho plazo mociones alternativas\} [2]

E.4.7.6. No aprobación de la moción de censura (EA: 33; CE: 1/3)

ORACIONAL[Si la moción de censura no fueselfuese aprobada $+\mathrm{f}$. determinativa + signatarios podrá presentar otra] [2]

E.4.7.7. Limitación para el planteamiento de la cuestión de confianza (EA: 33; CE: 115)

ORACIONAL $\{\mathrm{F}$. determinativa $+\mathrm{f}$. nominal + no podrá $+\mathrm{f}$. verbal: infinitivo $+\mathrm{f}$. relacional + esté en trimite una moción de censura\}][2]

E.4.8. Detención de los miembros del Consejo de Gobierno (EA: 25, 33; CE: 71, 102)

ORACIONAL $\{\mathrm{F}$. determinativa $+\mathrm{f}$. nominal + Gobierno no podrán ser detenidos ni retenidos por los presuntos actos delictivos cometidos en el territorio de la Región, sino en caso de flagrante delito, en fanto decide el Tribunal Superior de Justicia sobre su inculpación, prisión, procesamiento y juicio. Fuera de la Región la responsabilidad penal será exigible en los mismos términos ante la Sala de to Penal del Tribunal Supremo\}[2] \{Los diputados durante su nandato + f. adverbial: nolsólo + podrán ser detenidos en caso de flagrante delito $\}$ [3] $\{$ La responsabilidad $+\mathrm{f}$. adjetival + será exigible ante la Sala de lo Penal del Tribunal Constitucional $\}[2]$

F. TÍTULO III: DE LA ADMINISTRACIÓN DE JUSTICIA

F. I. Tribunal Superior de Justicia (EA: 34; CE: 123)

NOMINAL $\{$ El órgano jurisdiccional $\}[2]\{$ El Tribunal $+\mathrm{f}$. adjetival $\}[2]\{E l+\mathrm{f}$. nominal + superior $\}[2]$ VERBAL $\{$ Futuro $\}[3]\{$ [Es $\}[2]$

ORACIONAL $\{$ El Tribunal $+f$. adjetival + es el órgano jurisdiccional $\}$ [2]

F.2. Competencias de los órganos jurisdiccionales

F.2.1. Orden civil (EA: 35; CE: 149)

NOMINAL $\{$ Derecho $\}[4]\{$ F. nominal + civil $\}[4]\{$ Normas $\}[3]\{L a+$ f. nominal + de los derechos civiles, forales o especiales\}[3] \{F. nominal + juridico\}[3] \{Caso\}[2] \{Competencia\}[2] \{Materias\}[2] $\{$ Las normas de derecho $+\mathrm{f}$. adjetival $\}[2]$ \{Derecho foral o especial $\}[2]$ LLos recursos de $+\mathrm{f}$. nominal $\}[2]\{$ Las $+\mathrm{f}$. nominal + de las normas jurídicas $\}[2]\{\mathrm{F}$. nominal + relativas $\}[2]$

VERBAL $\{$ Presente: indicativo[2]/subjuntivo[1]\}[3]

F.2.2. Orden penal y social (EA: 35; CE: 149) 
NOMINAL LLegiskación $+\mathrm{f}$, adjetival $\}[4]\{$ Competencia $\}[2]\{$ Orden $\}[2]\{$ Orden $+\mathrm{f}$. adjetival $\}[2]\{$ Los recursos de $+f$. nominal $\}[2]\{\mathrm{F}$. nominal + pencl $\}[2]$

VERBAL $\{$ Presentc $\}[3]\{$ Se + presente $\}[2]$

F.3. Competencias del Tribunal Supremo (EA: 35; CE: 161)

ORACIONAL\{F. verbal: presente/futuro + conocer de los conflictos de competencia entre $+\mathrm{f}$. determinativa $+f$. nominal $+y+f$. determinativa $+f$. nominal $\}[2]$

F.4. Nombramicnto del Presidente del Tribunal Superior de Justicia (EA: 36; CE: 123)

ORACIONAL $\{$ El Presidente del Tribunal + $\mathrm{f}$. adjetival + será nombrado por el Rey a propuesta del Consejo General del Poder Judicial $\}[2]$

F.5. Nombramiento de magistrados, jueces y secretarios del Tribunal Superior de Justicia (EA: 36, 37; CE: 122)

NOMINAL\{La Ley Orgánica\}[4] \{Consejo General del Poder Judicial\}[3] \{La Ley Orgánicas del Poder Judicial $\}[3]$ \{Nombramiento\}[2] \{El órgano\}[2] \{Régimen $\}[2]$ \{Tribunal\}[2] \{La Comunidad Autónoma\}[2] \{Las Leyes Orgánicas del Poder Judicial y del Consejo General del Poder Judicial\}[2] $\{$ El estatuto jurridico de los $+\mathrm{f}$. nominal + de carrera $\}$ [2] \{Gobierno de $+\mathrm{f}$, determinativa $+f$. nominal\}[2] \{Personal al servicio de la Administración de Justicia $\}[2]\{F$. determinativa $+f$. nominal + de los jueces y magistrados\}[2] \{F. determinativa $+\mathrm{f}$. nominal + de magistrados, jueces, secretarios $\}[2]$ $\{F$. determinativa + estatuto de $+\mathrm{f}$. determinativa $+\mathrm{f}$. nominal $\}[2]$

VERBAL\{Futuro\}[5]

ORACIONAL $\{$ La ley orgánica $+f$, verbal: futuro $+\mathrm{f}$. determinativa + estatuto de $+\mathrm{f}$. determinativa $+\mathrm{f}$. nominal\}[2]

F.6. Ministerio Fiscal (EA: 38; CE: 124)

NOMINAL $\{$ Los principios de $+\mathrm{f}$. nominal $\}[5]$ \{Ministerio Fiscal $\}[4]\{\mathrm{F}$. nominal + del Ministerio Fiscal\}[4] \{La ley\}[3] \{La acción de la justicia en defensa de los + nominal\}[3] \{El Estado\}[2] \{Lcgalidad\}[2] \{Órganos\}][2] [F. nominal + del Ministerio Fiscal $\}[2]\{$ F. nominal + General del $+\mathrm{f}$. nominal $\}\{2\}\{$ F. nominal + del interés $+\mathrm{f}$. adjetival $\}[2]\{\mathrm{F}$. determinativa + funciones $\}[2]$

VERBAL\{Presente\}[3] \{Infinitivo\}[3] \{Futuro: activo[1]/pasivo[1]\}[2] \{Participio\}[2]

ORACIONAL \{ El Ministerio Fiscal tienen por misión + f. verbal: infinitivo\}[2]

F.7. Competencias de la Comunidad Autónoma en la Administración de Justicia (EA: 39; CE: 149, 152)

NOMINAL\{La Administración de Justicia\}[2] \{La Conunidad Autónoma\}[2] \{La Ley Orgánica del Poder Judicial $\}[2]\{$ La $+\mathrm{f}$. nominal + de las demarcaciones $+\mathrm{f}$. nominal + de $+\mathrm{f}$. determinativa $+\mathrm{f}$. nominal $[[2]$

VERBAL\{Presente: indicativo[2]/subjuntivo[1]\}[3] \{Infinitivo\}[2] \{Participio\}[2]

G. TÍTULO IV: HACIENDA Y ECONOMÍA

G. 1. Autonomía financiera (EA: 40; CE: 156)

ORACIONAL $\{$ La $+\uparrow$. nominal $+f$. verbal: presente/futuro + autonomía financiera $+f$. locución preposicional + los principios de coordinación con la $+\mathrm{f}$. nominal + estatal y de solidaridad entre todos los españoles [2]

G.2. Recursos conómicos y patrimonio de la Comunidad Autónoma (EA: 41, 42, Disp. Adic. Primera; $\mathrm{CE}: 132,142,157,158)$

ORACIONAL $\{\mathrm{F}$. determinativa + f: nominal + de la Comunidad Autonoma + f. verbal: estar: presente/futuro + constituido por: $\mathrm{F}$. nominal + procedentes de su patrimonio y/e $+\mathrm{f}$. adjetival $\mathrm{s} / \mathrm{f}$. nominal + de Derecho privado. F. nominal/f. verbal + cedidos total o parcialmente por el Estado. Recargos solure impuestos $+\mathrm{f}$. adjetival. F. determinativa + parficipaciones en los ingresos del Estado. El producto de operaciones de crédito. F. determinativa + asignaciones $+[\ldots]+$ los Presupuestos Generales del Estado. Transjerencias del Fondo de Compensación Interterritorial $\}[2]$ [La Hacienda de la Comunidad Autónoma esfa constituida por: Los ingresos procedentes de $+\mathrm{f}$. determinativa: su[2]/los $+\mathrm{f}$. nominal\} [3] [La Hacienda de la Comunidad Autónoma esta constituida por: El producto de las $+\mathrm{f}$. nominal $\}[2]$ \{F. verbal: ceder: presente: indicativo/subjuntivo $+e l+f$. adjetival + de los tributos $\}[2]\{\mathrm{F}$. verbal: poder: futuro/presente subjuntivo + establecer $+\mathrm{f}$. determinativa + asignación en los 
Presupuestos Generales del Estado\}[2] [Se cede a la Comunidad Autónoma de la Región de Murcia el rendimiento de los siguientes tributos: Impuestos sobre $+f$. nominal\}[5] \{El patrinonio de la Conunidad Autónoma de Murcia se compone de: Los bienes $+[\ldots]\}[3]$ \{El Patrimonio de la Contunidad Autónoma de Murcia se compone de: Los bienes que $+\mathrm{f}$. verbal: pretérito imperfecto subjuntivo $\}[2]\{L a / P o r+l e y+f$. verbal: deberá regularselregularä + el régimen juridico de los bienes de dominio público\}[2] \{ Por ley $+\mathrm{f}$. verbal: deberá regularselse regulará $+\mathrm{f}$. determinativa $+\mathrm{f}$. nominal \}[2]

G.3. Colaboración con el Estado en materia tributaria (EA: 43; CE: 133, 156)

NOMINAL $\{$ El Estado\}[4] \{Tributos\}[4] \{F. determinativa + administración\}[4] \{La Comunidad Autónoma $\}\{3]\{$ Sus fases de $+\mathrm{f}$. nominal $\}[3]\{L a+\mathrm{f}$. nominal + de los recursos tributarios $\}[3]\{L a+f$. nominal + de los tributos $+\mathrm{f}$. adjetival $\}[3]\{\mathrm{F}$. nominal + del Estado\}[3] [La colaboración $\}[2]$ $\{$ Delegación\}[2] \{Las leyes\}[2] \{Gestión, liquidación e inspección\}[2] \{Recaludación, gestión y liquidación\}[2] \{La administración de los tributos $+\mathrm{f}$. adjetival\}[2] \{Las corporaciones $+\mathrm{f}$. adjetival $\}[2]\{$ La recaudación de los $+\mathrm{f}$. nominal $+\mathrm{f}$. adjetival $\}[2]\{L a+\mathrm{f}$. nominal + de los tributos propios $\}[2]\{$ F. nominal + tributario $\}[2]\{\mathrm{F}$. adjetival + del Estado $\}[2]$

VERBAL\{Poder: futuro: podrá[1], podrán[3]/presente subjuntivo: pueda[2]/gerundio: pudiendo[1] + infinitivo\}[7] \{Presente: indicativo[1]/subjuntivo[3]\}[4] \{Corresponder: presente: corresponde?2]/corresponderá[1]\}[3]

ORACIONAL\{F. verbal: corresponde: presente[2]/futuro[1] $+a+f$. determinativa $+f$. nominal $\}[3]\{E n$ los demás casos, dicha administración corresponderá al Estado, sin perjuicio de la $+\mathrm{f}$. nominal + que la Región pueda + f. verbal: infinitivo\}[2] \{Las Comunidades Autónomas podrán + f. verbal: infinitivo\}[3]

G.4. Recurso contencioso-administrativo (EA: 44; CE: 153)

NOMINAL $\{$ Jurisdicción $\}[2] \quad\{$ La Comunidad Autónoma $\}[2] \quad\{\mathrm{F}$. nominal + contenciosoadministrativo $\}[2]\{\mathrm{F}$. nominal + de los órganos de la Comunidad Autónoma $\}$ [2]

VERBAL Futuro\}[2]

G.5. Presupuesto de la Comunidad Autónoma

G.5.1. Elaboración del Presupuesto (EA: 46; CE: 134)

ORACIONAL\{Corresponde al (Consejo de) Gobiemo la elaboración del Presupuesto de +1 . detcrminativa $+f$. nominal $+y$ a la $+\mathrm{f}$. nominal + su examen, enmienda y aprobación $\}[2]$

G.5.2. Presupuesto anual (EA: 46; CE: 134)

ORACIONAL $\{$ El Presupuesto tendrá carácter anual $\}[2]$

G.5.3. Plazo de presentación (EA: 46; CE: 134)

ORACIONAL Activa/pasiva: El Gobierno/El Presupuesto + f. verbal: deberá presentarl será presentulo + el Presupuestolpor el Gobiemo\}[2]

G.5.4. Contenido del Presupuesto (EA: 46; CE: 134)

ORACIONAL $[F$. determinativa $+f$. nominal/Se + incluirún la totalidad de los gastos e ingresos de $+\mathrm{f}$. determinativa $+f$. nominal $+\mathrm{f}$. verbal: consignar: $s e+$ futuro/gerundio + el importe de los beneficios fiscales que afecten a tributos\} [2]

G.5.5. Aprobación del Presupuesto (EA: 46; CE: 134)

ORACIONAL \{ Si la Ley de Presupuestos no + f. verbal: futuro subjuntivo: fuera aprobada/se aprobara + amtes del primer día del ejercicio económico correspondiente $+\mathrm{f}$. verbal: futuro + automáticamente prorrogada la del ejercicio anterior hasta la aprobación del nuevo][2]

G.6. Emisión de deuda pública (EA: 47; CE: 135)

ORACIONAL $\{$ El (Consejo de Gobiemo autorizado por ley + f. verbal: futuro + emitir deuda pública + f. relacional: $y / o+f$. verbal: infinitivo + crédito $\}[2]\{$ El Consejo de Cobiemo podrá $+[$. verbal: participio + operaciones de crédito por plazo superior a un año] [2]

G.7. Instituciones públicas de crédito (EA: 48; CE: 149) 
NOMINAL\{Competencia $\}[2]\{$ Crédito\}[2] $\{$ El Estado\}[2] \{Ahorro + f. adjetival\}[2] [Los principios $d e+f$. nominal $+f$. adjetival $\}[2]\{E l+f$. nominal + de instituciones públicas de crédito y ahorro terriloriales $\}[2]\{L a+f$. nominal + del ahorro regional $\}[2]\{L a+f$. nominal + de la inversion $\}[2]$ VERBAL\{Presente: indicativo[1]/subjuntivo[2]\}[3] \{Futuro: indicativo[2]/subjuntivo [1]\}[3] \{ Infinitivo\}[2]

ORACIONAL [ La Comunidad Autónoma $+\mathrm{f}$. verbal: futuro $]$ [2]

G.8. Creación de cmpresas públicas (EA: 17, 48; CE: 128)

NOMINAL,FF. nominal + publico $\}[4]\{$ El sector $+\mathrm{f}$. adjetival $\}[3]\{$ Actividad $\}[2]\{$ Caso $\}[2]\{$ La ejecución\}[2] \{Enpresas\}[2] \{La Región $\}[2]$ [El sector público\}[2] $\{$ La + f. nominal + de Murcia $\}[2]$ $\{L a+\mathrm{f}$. nominal + de los sectores econónicos $\}[2]\{\mathrm{F}$. nominal + esenciales $\}[2]$ [F. nominal + economico $][2]$

VERBAL\{Futuro: indicativo[5]/subjuntivo[1]\}[6] \{Presente: indicativo[3]/subjuntivo [1]\}[4] \{Se + presente[1]/ futuro[2]\}[3] \{Podrá + infinitivo\}[2] \{Se podrá + infinitivo\} [2] \{Establecido\}[2]

ORACIONAL $\{$ La Comminidad Autónoma de Murcia podrá + infinitivo\}[2] [Mediante ley se podrá + infinitivo\}[2]

G.9. Participación en la empresa. Acceso de los trabajadores a la propiedad de los medios de producción (EA: 49; CE: 129 )

ORACIONAL $\{\mathrm{F}$. determinativa + f. nominal + promoverá las diversas formas de participación en la enpresa y fomentari, medianle una legislación adecuada, las cooperativas. También $+\mathrm{f}$. verbal: futuro + los $+f$. nominal + que faciliten el acceso de los trabajadores a la propiedad de los medios de producciónl[2]

G. 10. Modernización y desarrollo de sectores económicos (EA: 49; CE: 130)

ORACIONAL\{F. determinativa $+f$. nominal + atenderá la modernización y desarrollo de todos los sectores económicos y, en particular, de la agricultura, de la ganadería, de la pesca y de la artesanía, a fin de equiparar el nivel de vida de todos los $+\mathrm{f}$. adjetival $\left.{ }^{\mathrm{s}}\right\}[2]$

H. TÍTULO V: RÉGIMEN JURÍDICO

H.1. CAPÍTULO I: DE LA ADMINISTRACIÓN PÚBLICA REGIONAL

H.1.1. Principios de la Administración Pública (EA: 51; CE: 103)

ORACIONAL $\{$ La Administración pública $+\mathrm{f}$. verbal: presente/futuro $+\mathrm{f}$. preposicional + los principios de eficacia. jerarquía. coordinación, descentralización y desconcentración \}[2]

H.1.2. Regulación por ley del régimen jurídico de la Administración pública (EA: 52: CE: 103)

NOMINAL $\{$ La ley $][3]$ F. nominal + público $\}[3]\{$ Ejercicio $\}[2]\{$ Los principios de $+f$. nominal $\}[2]\{\mathrm{F}$. determinativa + función $\}[2]\{F$. nominal + del Estado $\}[2]\{E l+f$. nominal $+d e+f$. determinativa + funcionarios $\}[2]\{\mathrm{F}$. determinativa $+\mathrm{f}$. nominal + de la Administración $+\mathrm{f}$. adjetival $\}[2]$

VERBAL\{Presente pasivo: son + participio\}[3] \{Regular: futuro: activo: regulará[1]/ pasivo: será regulado[!]\}]2]

ORACIONAL\{F. detcrminativa + f. nominal + de la Administración $+\mathrm{f}$. adjetival $+\mathrm{f}$. verbal: pasiva: presente/fuluro + f. preposicional + ley\}[2] \{Activa/pasiva: La ley/El + f. nominal + regularälserá regulado + de $+\mathrm{f}$. determinativa + fincionarios $\}[2]$

H.2. CAPÍTULO 1I: DEL CONTROL SOBRE LA ACTIVIDAD DE LOS ÓRGANOS DE LA COMUNIDAD AUTÓNOMA.

H.2.1. Sometimiento al control del Tribunal Constitucional y a Ia jurisdicción contenciosoadministrativa (EA: 53; CE: 153)

ORACIONAL $\{L a+\mathrm{f}$, nominal + de $l a+\mathrm{f}$. nominal + Autónoma $+\mathrm{f}$. verbal: se someterán/estarán sontetidas + al commol de $+f$. determinativa $+f$. nominal $\}[2]$ \{ El control de la actividad de los órganos de. las Comumidades Autónomas se ejercerá: Por $+\mathrm{f}$. determinativa $+\mathrm{f}$. nominal $\}$ [2] \{La actividad de la $+\lceil$. nominal + autónoma $+\mathrm{f}$. verbal: futuro $+\mathrm{f}$. preposicional: porlde + la jurisdicción contenciosoadministrativa $\}[2]$ [F. determinativa + f. nominal + de la Comunidad Autónoma $+\mathrm{f}$. verbal: se + futuro + r. preposicional: porlde + el Tribunal Constitucional $\}[2]$ 
H.2.2. Control económico y prcsupuestario por el Tribunal de Cuentas del Estado (EA: 54; CE: 136, 153)

NOMINAL $\{$ El Tribunal de Cuentas $\}[9]\{F$. determinativa + f. nominal + del Tribunal de Cuentas $\}[6]$ $\{$ F. detcrminativa + I. nominal + del Estado\}[5] \{El órgano\}[3] \{Las Cortes Generales\}[3] \{F. nomina] + económico\}[3] [Funciones\}[2] \{La Asamblea Regional\}[2] \{El control económico y presupuestario $d e l a+[$. nominal $\}\{2]\{\mathrm{F}$. nominal + regional $\}[2]\{\mathrm{F}$. nominal + del sector público $\}[2]\{\mathrm{F}$. determinativa + informe $\}[2]$

VERBAL\{Futuro: indicativo[14]/subjuntivo: perfecto[1]\}[15] \{Futuro: activo[13]/ pasivo[2]\}[15] \{Presente: indicativo[2]/ subjuntivo[1]\}[3] $\{\mathrm{Se}+$ futuro: indicativo[3] /subjuntivo: futuro perfecto[1]\}[2] \{ Seri + participio\} [2] \{ Se ejercerá $\}[2]$

ORACIONAL $\{$ El control económico y presupuestario de la $+\mathrm{f}$. nominal + se ejercerí por el Tribunal de Cuentas $\}[2]\{$ El Tribunal de Cuentas $+\mathrm{f}$. verbal: futuro $\}[2]\{\mathrm{F}$. determinativa + informe $+\mathrm{f}$. verbal: será remitido/renitirá + a las Cortes Generales\} [2]

I. TÍTULO VI: DE LA REFORMA DEL ESTATUTO

1.1. Procedimiento de reforma (EA: 55; CE: 147)

ORACIONAL $\{$ La reforma de $+\mathrm{f}$. determinativa + Estatuto se ajustará al procedimiento $\}$ [2]

1.2. Iniciativa de reforma (EA: 55 ; CE: $87,166,167$ )

NOMINAL $\{$ La Asamblea\}[5] \{Gobierno\}[4] \{Mayoria\} $\}[4] \quad\{L e y\}[3] \quad\{E l$ Congreso $\}[3] \quad\{$ El Gobiemo\}[3] \{La inicialiva\}[3] \{Miembros\}[3] \{La Asamblea Regional\}[3] \{F. determinativa + proyecio de $+\mathrm{F}$. nominal $\}[3][\mathrm{F}$. determinativa + articulo $\}[3]\{\mathrm{F}$. determinativa + Camara $\}[3]\{\mathrm{F}$. dcterminativa +1 . nominal + de reforma $\}[3]\{$ La Constitución $\}[2]$ [El Senado $\}[2]\{$ Las Cortes Generales\}[2] \{Mayoria de tres quintos $\}[2]\{$ El proyecto de reforma\}[2] \{El articulo $+f$. adjetival\}[2] $\{U n+\mathrm{i}$. nominal + de ley $\}[2]\{\mathrm{F}$. determinativa $+\mathrm{f}$. nominal + de reforma constifucional $\}[2]\{\mathrm{F}$. determinativa + aprobación $\}[2]\{\mathrm{F}$. determinativa + f. nominal + de la Asamblea Regional $\}[2]$

VERBAL\{Participio\}[10] \{Futuro: activo[8]/pasivo[1]\}[9] \{Será + participio\}[3] \{Presente: indicativo[1]/ subjuntivo [2]\}[3] \{Gerundio\}[2] \{Infinitivo\}[3] \{Aprobar: pasivo: infinitivo: ser aprobado[1]/futuro: será aprobado[1]\}[2] \{Corresponder: presente: corresponde[1]/futuro: corresponderá[1]\}[2] \{Previsto\}[2] \{Podrán + infinitivo\}[2] $\{$ Se + futuro\}[2]

ORACIONAL\{La iniciativa + f. verbal: futuro $\}[3]$ \{La iniciativa $+f$. verbal: corresponder: presente/futuro $+a+f$. determinativa $+f$. nominal $\}[2]$ [El proyecto de reforma $+f$. verbal: será aprobadoldeberán ser aprobados + por mayoria de tres auintos de $+f$. determinativa $+f$. nominal $\}[2]$ \{Las Asambleas de las Comunidades Autónomas podrán + infinitivo\}[2]

J. DISPOSICIONES ADICIONALES

J. !. Altcración de los límites territoriales (EA: Disposición Adicional Segunda; CE: /4I)

ORACIONAL $\{$ Curkquier alteración de los límites $+f$. adjetival $+\mathrm{f}$. verbal: futuro $+[\ldots]+f$. preposicional: delpor + las Cortes Generales, + f. preposicional + ley orgainica\} [2]

K. DISPOSICIONES TRANSITORIAS

K. . Traspaso de competencias (EA: Disposición Transitoria Quinta; CE: 147)

NOMINAL\{La Comisión Mixta\}[9] \{Traspaso\}[8] \{La Comunidad Autónoma\}[7] \{Los servicios\}[6] $\{$ El traspaso de + l. nominal\}[5] \{La competencia $\}[4]$ \{Transferencias $\}[4]\{$ Comisión + f. adjetival $\}[4]$ $\{\mathrm{F}$. determinativa + Estatuto $\}[4]\{\mathrm{F}$. determinativa + f. nominal $+\operatorname{del}$ Estado\}[4] \{Acterdo\}[3] \{Decreto\}[3] \{El Gobiemo\}[3] \{El traspaso de los servicios\}[3] \{Los traspasos de medios + f. adjctival][3] [F. nominal + establecido\}[3] \{Las bases\}[2] [El contrato\}[2] \{Consejo\}[2] \{Derech $\}[2] \quad\{$ Propuesta\}[2] \{Bienes del Estado\}[2] $\{$ El presente Estatuto\}[2] \{Comisiones sectoriales\}[2] \{La Commuidad Autónonta de Murcia\}[2] \{El Boletín Oficial de $+\mathrm{f}$. determinativa $+\mathrm{f}$. nominal\}[2] \{Carâter $+[$. adjetival $\}[2]$ L La Comisión Mixa $+\mathrm{f}$. adjetival\}[2] [El traspaso de los servicios + l. adjetival + a las + f. pronombre/f. nominal $\}[2]\{E l$ término + f. adjetival $\}[2]\{E l+f$. nominal + maximo $\}[2]\{\mathrm{gF}$. nominal + de transferencias $\}[2]\{\mathrm{F}$. determinativa + certificación $\}[2]\{\mathrm{F}$. dcterminaliva + f. nominal + de la Región de Murcia $\}[2]$ [F. nominal + correspondiente $\}[2]$ 
VERBAL\{Futuro\}[19] \{Participio\}[18] \{Infinitivo\}[17] \{Presente: indicativo[3]/ subjuntivo[5]\}[8] \{Establecer: futuro: establecerá[2]/participio: establecido[4]\}[6] $\{$ Se + futuro[4]/subjuntivo: pretérito imperfecto[I]/presente[1]\}[6] $\{$ Deba + infinitivo\}[4] \{Asumir: futuro: asumirá[1]/participio: asumidas[1]\}[2] \{Dela ser\}[2] \{Deberá contener $\}[2]$ \{Estará + participio\}[2] \{Gerundio\}[2] [Ser: presente: es[1]/futuro: serí[3]/ pretérito imperfecto subjuntivo: fuera[1]\}[2]

ORACIONAL\{ $\mathrm{F}$. verbal: presente/futuro + el traspaso de los servicios $+\mathrm{f}$. adjetival + a las $+\mathrm{f}$. pronombre/f. nominal][2]

L. FÓRMULA FINAL (EA; CE)

ORACIONAL $\{$ Por tanto, mando a todos los españoles, particulares y autoridades, que guarden y hagkin guardar esia $+f$, nominal \}[2]

M. REFERENCIAS EXTERNAS A LA CONSTITUCIÓN ESPAÑOLA E INTERNAS AL ESTATUTO DE AUTONOMIA DE LA REGIÓN DE MURCIA

ORACIONAL $\{[\ldots]+$ de acuerdo con el articulo $+f$ adjetival + de la Constitución $\}[10]^{10}$ (EA: 23)

ORACIONAL $\{[\ldots]+$ de acuerdo con lo $+\mathrm{f}$. verbal: participio + en el articulo $+\mathrm{f}$. determinativa + de la Constitución y el articulo $+\mathrm{f}$. determinativa + de la Ley Orgánica del Tribunal Constitucional $\}$ [2] (EA:

32)

ORACIONAL\{[...] + de acuerdo con lo dispuesto en el artículo $+f$. determinativa + de la Comstitución $\}[3]\{[\ldots]+$ de acuerdo con lo dispuesto en la Constitución $\}[4]\{[\ldots]+$ lo dispuesto en la Constitución][2] (EA: Preám., 10, 16, 23,32)

ORACIONAL\{[... $\}+$ de acuerdo con lo previsto en el artículo $+\mathrm{f}$. determinativa + de la Constitución $\}[2]\{[\ldots]+$ lo previsto en el articulo $+\mathrm{f}$. determinativa + de la Constitución $\}[2]\{[\ldots]+$ lo previsto en el mímero $+\int$. determinativa + del artículo + f. determinativa + de la Constitución $\}[2]\{[\ldots]$ + previsto en el articulo $+\mathrm{f}$. determinativa + de la Constitución $\}[2]\{[\ldots]+$ lo previsto en $+\mathrm{f}$. determinaliva + articulo $\}[3][1 \ldots]+$ previsto en el mimero $+\mathrm{f}$. determinativa + del apartado $J$ del articulo 149 de la Constitución\}[2] (EA: Preámbulo, 12, 13, 19, 23, 32, 53, 55)

ORACIONAL $[1 . .]+$. de acuerdo con los nímeros $+\mathrm{f}$. determinativa + del apartado I del artículo 149 de la Constitución\}[2] (EA: 10, II)

ORACIONAL $[1 \ldots]+$ en los términos de lo dispuesto en los artículos 38,131 y números $1 /$ y 13 del apartado I del articuto 149 de ia Constitución $\}[2]\{[\ldots]+$ en los términos del artículo $+\mathrm{f}$. determinativa + de la Constitución $\}[2]\{[\ldots]+$ en los términos $+[\ldots]+f$ preposicional: en[1]/de[2] + el artículo $+f$. determinativa + de la Constitución\}[3] (EA: 10, 11,34, 10, 23)

ORACIONAL[[..] + de conformidad con lo $+[\ldots]+$ el arliculo $+\mathrm{f}$. determinativa + de la Constitución $\}[2]\{[\ldots]+$ de conformidad con el número $+\mathrm{f}$. determinativa + del apartado I del articulo 149 de la Constitución $\}[2]\{[\ldots]+$ de conformidad con la Constitución $\}[4]$ (EA: II, I2, Disposición Adicional.)

ORACIONAL $\{[\ldots]+$ a que se refiere el articulo + f. determinativa + de la Constitución $\}[2]$ (EA: 15, 23)

ORACIONAL $\{[\ldots]+\sin$ perjuicio de lo $+\mathrm{f}$. verbal: participio + en la Constiucion $\}[3]\{[\ldots]+\sin$ perjuicio de lo +5 . verbal: participio + en el número $+f$ adjetival + del arfículo 149 de la Constiución $\}[2]\{[\ldots]+$ lo establecido en la Constitución $\}[2]\{[\ldots]+$ establecido en los números $+\mathrm{f}$. determinativa $+y+\int$. determinativa + del artículo $+\mathrm{f}$. determinativa + de la Constitución $\}[2]\{[\ldots]+$ establecido en el articulo $+f$. determinativa + de la Constitución] [2] (EA: 7, 9, 10, 11, 13, 55)

ORACIONAL $\{[\ldots]+$ de acuerdo con la Constitución y el presente Estatuto $\}[2]\{[\ldots]+$ de acuerdo con el presente Estatuto $\}[3]\{[\ldots]+$ de acuerdo con la Constitución, + f. adjetival + Estatuto\}[2] (EA: Préimbulo, $1,34,40)$

ORACIONAL $\{[\ldots]+$ la Constitución + f. verbal: presente $\}[3]$ (EA: Preámbulo, 9, 22)

${ }^{16}$ Esta cstructura aparece dicz veces, pero se ha obviado repetirla ya que también está incluida en los casos que le siguen. Este ejemplo no puede ubicarse en ningún otro, por lo tanto, se ha preferido mantenerlo de esic modo. 


\section{Conclusiones}

Del desarrollo anterior se desprende una conformación prototípica de la sintagmática enunciativo-legal seleccionada. Las estructuras lingüísticas funcionales nos conducen a plantear una convergencia en el casi estatismo de los textos. Se ha verificado que los dominios precisan de expresiones lingüísticas lexicalizadas de diferente forma, que pueden ser univerbales o pluriverbales; éstas han sido presentadas como unidades léxicas operativas de la textualidad legal basadas en estructuras permanentes bajo unos ámbitos temáticos, proponiendo así un modelo de formalización en la variación de los componentes léxicos en su representación morfosintáctica. Podemos hablar de expresiones privilegiadas en las que las unidades pluriverbales presentan tal número de apariciones que pueden integrarse en el grupo de unidades operativas en el ámbito jurídico.

Como resultado del análisis intertextualidad encontramos 607 formas oracionales, de las que 283 son distintas. De los 168 dominios construidos en 19 de ellos no se presentan formas oracionales semejantes o idénticas entre el EA y la CE. En doce ocasiones se interconexionan los artículos del EA con el 149 de la CE, seguidos por el 147 y 148, los tres incluidos en el capítulo tercero: «De las Comunidades Autónomas». El mayor número de alusiones hacia la $\mathrm{CE}$ están en el artículo 10 (competencias exclusivas de la Comunidad Autónoma), en el artículo 23 (competencias de la Asamblea Regional), en el 33 y 32 (Consejo de Gobierno), en el 11 (materias de desarrollo legislativo y ejecución regional) y en el Preámbulo. El contenido analizado de los dos textos legales hace ver como las proyecciones hacia el EA adquieren valor deontológico, por ello es interesante decir que en él la palabra «Constitución» aparece en cuarenta ocasiones ${ }^{11}$. Por lo tanto, exponemos la siguientc conclusión: la CE es paradigma lingüístico en su diseño discursivo textual del EA y, previsiblemente, del resto de Estatutos vigentes en otras Comunidades Autónomas.

\section{Referencias bibliográficas:}

Alarcos Llorach, E. (1994): Gramática de la Lengua Española. Madrid: Espasa Calpe.

Alvar Ezquerra, M. (1976): Proyecto de lexicografía española. Barcelona: Planeta. Alvar Ezquerra, M.(1993): Lexicografía descriptiva. Barcelona: Bibliograf. Cabré Castellví, Ma . T. (1993): La terminología. Teoría, Metodología, Aplicaciones. Barcelona: Antártida/Empúries. 1993.

\footnotetext{
"Hay una aparición de la palabra «constitución» pero con un significado de acción: «la constitución de la Asamblea Regional» (Disposición Transitoria Segunda).
} 
Cifuentes Honrubia, J. L. (1994): Gramática Cognitiva. Fundamentos Críticos. Madrid, Eudema.

Constitución española y estatuto de autonomía de la región de murcia (1998): Cartagena: Asamblea Regional de Murcia.

Coseriu, E. (1977): Principios de semántica estructural. Investigación metodológica. Madrid: Gredos.

Dijk, T. A. Van (1996) (1983): La ciencia del texto. Barcelona: Paidós Comunicación.

Duchacek; O. (1970): «Quelques observations sur la structure du lexique». Mélanges 6: 200-210.

Ferenczi, T. (1976): «Jean Paulhan et le discours politique». Jean Paulhan le souterrain. Eds. T. Ferenczi et al. Paris: U.G.E. 225-249.

García Berrio, A.; Albaladejo Mayordomo, T. (1983): «Estructura composicional. Macroestructuras». ELUA 1: 127-180.

Hernández Alonso, C. (1996): Gramática funcional del español. Madrid: Gredos.

Martín, J., Ruiz, R., Santaella, J. y Escánez, J. (1996): Los lenguajes especiales. [Lenguaje jurídico-administrativo, Lenguaje científico-técnico. Lenguaje humanístico. Lenguaje periodístico y publicitario. Lenguaje literario]. Granada: Comares.

Martínez Marín, J. (1997): «El lenguaje administrativo. Descripción y norma». LEA XIX/2: 215-228.

Pcrona Sánchez, J. (1993): «Estructuras pragmáticas y estrategias textuales en la tradición foral de los manuscritos del Fuero de Zamora». Voz y Letra IV/1: 129192.

Pottier, B. (1971): Gramática del español. Madrid: Ediciones Alcalá, S.A.

Pottier, B. (1976): Linguiistica General. Teoría y descripción. Madrid: Gredos.

Potticr, B. (1993): Semántica general. Madrid: Gredos.

Provencio Garrigós, H. (2000): «Integración de procesos lógico-cognitivos en la construcción textual». Revista de Investigación Lingüística. (En prensa):

Ramón Trives, E. (1999): "Aspectos cognitivos en la aproximación integrada a la dinámica léxico-discursiva». Estudios de Lingüistica Cognitiva I Ed. J. L. Cifuentes Honrubia. Alicante: Universidad de Alicante. 149-170.

Rasticr, F. (1995): «La sémantique des thèmes ou le voyage sentimental». L'Analyse thématique des données textuelles. L'exemple des sentiments. Ed. É. Martin. Paris: CNRS-INaLF, Didier Ėrudion. 223-249.

Salvador, G. (1992): Política lingüística y sentido común. Madrid: Istmo.

Thom, R. (1985): Parábolas y Catástrofes. Entrevista sobre matemáticas, ciencia y filosofia. Barcelona: Tusquets Ediciones.

Ullman, S. (1977): Lenguaje y estilo. Madrid: Aguilar. 